Louisiana State University

LSU Digital Commons

1974

\title{
Radical Brominations of Alkanic Positions by Bromine and by $\mathrm{N}$ - Bromosuccinimide.
}

Yu-sun Lee

Louisiana State University and Agricultural \& Mechanical College

Follow this and additional works at: https://digitalcommons.Isu.edu/gradschool_disstheses

\section{Recommended Citation}

Lee, Yu-sun, "Radical Brominations of Alkanic Positions by Bromine and by N-Bromosuccinimide." (1974). LSU Historical Dissertations and Theses. 2617.

https://digitalcommons.Isu.edu/gradschool_disstheses/2617

This Dissertation is brought to you for free and open access by the Graduate School at LSU Digital Commons. It has been accepted for inclusion in LSU Historical Dissertations and Theses by an authorized administrator of LSU Digital Commons. For more information, please contact gradetd@lsu.edu. 


\section{INFORMATION TO USERS}

This material was produced from a microfilm copy of the original document. While the most advanced technological means to photograph and reproduce this document have been used, the quality is heavily dependent upon the quality of the original submitted.

The following explanation of techniques is provided to help you understand markings or patterns which may appear on this reproduction.

1. The sign or "target" for pages apparently lacking from the document photographed is "Missing Paga (s)". If it was possible to obtain the missing paga(s) or section, they are spliced into the film along with adjacent pages. This may have necessitated cutting thru an image and duplicating adjacent pages to insure you complete continuity.

2. When an image on the film is obliterated with a large round black mark, it is an indication that the photographer suspected that the copy may have moved during exposure and thus cause a blurred image. You will find a good image of the page in the adjacent frame.

3. When a map, drawing or chart, etc., was part of the material being photographed the photographer followed a definite method in "sectioning" the material. It is customary to begin photoing at the upper left hand corner of a large sheet and to continue photoing from left to right in equal sections with a small overlap. If necessary, sectioning is continued again - beginning below the first row and continuing on until complete.

4. The majority of users indicate that the textual content is of greatest value, however, a somewhat higher quality reproduction could be made from "photographs" if essential to the understanding of the dissertation. Silver prints of "photographs" may be ordered at additional charge by writing the Order Department, giving the catalog number, title, author and specific pages you wish reproduced.

5. PLEASE NOTE: Some pages may have indistinct print. Filmed as received.

Xerox University Microfilms

300 North Zoob Road

Ann Arbor, Mlchigan 48106 


$$
74-24,786
$$

LEE, YU-SUn, 1941-

RADICAL BROMINATIONS OF ALKANIC POSITIONS BY

BROMINE AND BY N-BRONOSUCCINIMIDE.

The Louisiana State University and Agricultural and Mechanical College, Ph.D., 1974

Chemistry, organic

University Microfilms, A XEROX Company , Ann Arbor, Michigan 


\title{
RADICAL BROMINATIONS OF ALKANIC POSITIONS BY
}

BROMINE AND BY N-BROMOSUCCINIMIDE

\author{
A Dissertation \\ Submitted to the Graduate Faculty of the \\ Loulsiana State University and \\ Agricultural and Mechanical College \\ in partial fulfiliment of the \\ requirements for the degree of \\ Doctor of Philosophy
}

in

The Department of Chemistry

\author{
by \\ Yu-Sun Lee \\ B.S., Chung Yuan Christian College of Science and Engineering, 1965 \\ May, 1974
}


To my parents

11

Reproduced with permission of the copyright owner. Further reproduction prohibited without permission. 


\section{ACKNOWLEDGEMENT}

The author wishes to acknowledge his greatest appreclation to Profegsor James G. Traynham for his guidance, encouragement, and inspiration.

Sincere appreciation is also expressed for the cooperation of Mr. George Sexton and Mr. Ralph Seab for their fast services in repairing the ge instrument and in preparing new columns.

The encouragement of my wife, Ya-wen Shth Lee, contributed Immeasurably to this work.

The author sincerely appreclates the financial support from Loufsiana State UnIversity during his graduate study and the financial ald in preparation of this Dissertation by the Charles E. Coates Memorial Fund, donated by George E. Coates and admintstered by the LSU Foundation. 


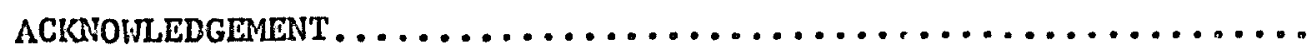



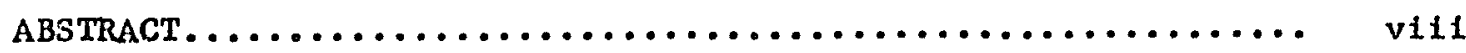

I. INTRODUCTION........................... 1

A. Evidence of bridging by neighboring bromine in free-radical reactions..............

B. Evidence against bridging by neighboring bromine in free-radical reactions.............. 11

II. RESULTS AND DISCUSSION..................... 18

III. EXPERTMENTAL......................... 38

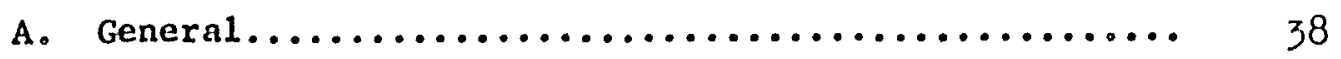

B. Syntheses............................. 39

1. Preparation of $1,1-\mathrm{d} 1 \mathrm{~b}$ romobutane........... 39

a. 2-Bromopentanolc acid............... 39

b. Silver 2 -bromopentanoate.............. 40

c. $1,1-$ Dtbromobutane................... 40

2. Preparation of trang-1,2-dibromocyclopentane... 41

3. Preparation of exo-2-bromonorbornane......... 42

4. Preparation of endo-2-bromonorbornane........ 42

5. Preparation of 1-bromonorbornane............ 44

a. exo-2-Norbornyl formate.............. 44

b. 2 -Norbornanone..................... 44

c. Phosphorus pentabrom1de............... 45

d. 2,2-Dtbromonorbornane................ 45

e. 1 -Bromonorbornane................... 46

C. Bromination......................... 47

1. Materlals........................ 47

2. General procedure for bromination........... 4,3

a. Bromination of butyl bromlde by bromine.... M)

b. Bromtnation of butyl bromide by NBS ...... 1,1 
c. Competitive bromination of butyl bromide and cyclohexane by bromine............. $; z^{\prime}$

d. Competitive bromination of butyl bromide and cyclohexane by NBS ................ ;;

e. Competitive bromination of cyclopentane and cyclohexane by bromine............

f. Competitive bromination of cyclopentane and cyclohexane by NBS............... 54

g. Bromination of cyclopropane by kromine..... i ij

h. Bromination of cyclopropane by NBS........ 'j'

1. Bromination of norbornane by bromine....... , ,

j. Bromination of norbornane by NBS .........

$k$. Preparation of exo- and endo-2bromonorbornanes by Koch 1 reaction........ 1;6

2. Bromination of ethylbenzene by NBS........ 57

D. Miscellaneous Control Experiments.............. 57

1. Control reaction for bromination of butyl bromlde by bromine and by NBS .............. 57

2. Control reaction for bromination of cyclohexane by NBS ........................ 58

3. Control reaction for bromination of cyclopropane by bromine.................... 58

4. Addition of bromine to norbornene........... 58

5. Bromination of exo- and endo-2bromonorbornane by bromine............... 58

6. Control reaction of bromination of exo- and endo-2-bromonorbornanes by bromtne.......... 59

REFERENCES ................................. 60

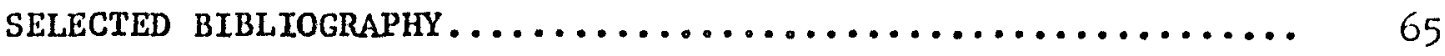

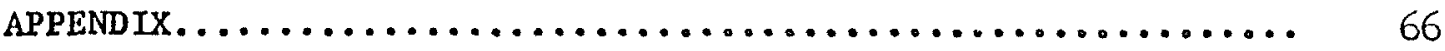

vITA.................................... 72 


\section{LIST OF TABLES}

TABLE

NUMBER

PAGE

I. Relative reactivities in gas phase chlorination..... 1

II. Selectivities in gas phase bromination............

III. Relative reactivities in liquid phase halogenation of 1 -halobutane.....................

IV. Isotope effect in the radical addition of $\mathrm{HBr}$

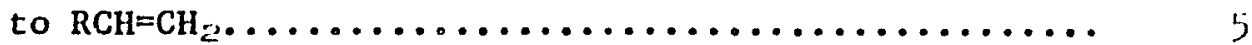

V. Competition reactions of stereolsomertc 3 -haloand 3 -methylthio-2-butanols................

VI. Ratlo of diastereomeric 2,3-dibromobutanes from the photobromination of 2 -bromobutanes............

VII. Isomer distribution for the bromination of butyl bromide with molecular bromine................

VIII. Isomer distribution for AIBN initiated bromina-

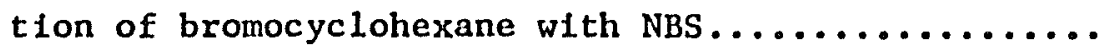

IX. Competitive brominations of butyl bromide and cyclohexane..........................

X. Isomeric product distributions obtained from brominations of butyl bromlde with molecular bromtne...............................

XI. Isomer distribution in the photoinitiated bromination of butyl bromide with NBS in acetonitrile....

XII. Isomer distribution in the AIBN-initiated bromination of butyl bromide with NBS in acetonitrile.....

XIII. Isomeric product distributions obtained from photoinftiated NBS bromination of butyl bromide in acetonitrile..........................

XIV. Bromination of (+)-1-öomo-2-methylbutane by NBS.... 
XV. Bromination of $(+)-1-$ bromo-2-methylbutane by bromine..............................

XVI. Relattve rates of competitive bromination of chlorocycloherane and cyclohexane............ 34

XVII. Relative rates of competitive bromination of ethylbenzene and toluene................ ;h

XVIII. Relative rates of alkanic positions vs. toluene toward $\mathrm{N}$-bromo amides................... 35 


\section{ABSTRACT}

During the past decade, the details of mechantsm of radical brominations of alkanes, and in particular the influence of a bromo substituent on the selectivity in the hydrogen-abstraction step, have been studied and debated by several groups of investfgators. Central to the controversy is the mechanism of bromination by $\underline{N}$-bromosuccinimide (NBS), for some of the proposals are supported almost solely by the presumed sameness of bromination mechanism for both molecular bromine and NBS reagents. That sameness was established for brominations of benzylic positions by kinetic studies and has been assumed for other systems. Some earlier data in the literature on bromocyclohexane halogenations Indicate that the isomer distribution obtained with NBS reagent is closer to that obtained with chlorine than to that with bromine, even though the data were presented from the viewpoint that bromine and NBS brominations involve the same hydrogen-abstracting and bromine-transfer species. Our study suggests that a different mechanism is Involved when bromination occurs on alkantc posttions. That is, the hydrogen-abstracting agent is different when molecular bromine is used than when NBS is used. Both by intermolecular competition experiments (butyl bromide vs. cyclohexane and cyclohexane vs, cyclopentane) and by reactions with single substrates (cyclopropane and norbornane), the two brominating reagents have been shown to be different. With cyclopropane, the identities of the radicals which attack the substrate axe shown to be different from the two reagents, and with norbornane, the identities of the bromine-transfer reagents which react with the alkyl radical are shown to be different. 


\section{INTRODTCTION}

A. Evidence of bridg1ng by neighboring bromine in froo-radical reactiong

There have been several studies of the Influence of an electronegative subst1tuent on the attack of halogen atoms at different positions in an allphatic system. Two factors, polar effects and $\mathrm{C}-\mathrm{H}$ bond strengths, generally influence the relative reactivities of the different sites toward halogen atoms; In other words, they determine the distribution of possible radical intermediates and thereby determine the isomeric distribution of halide products.

The reactivity of $\alpha$-hydrogen with halogen atoms is increased by the electronegative substituent which tends to lower the $\mathrm{C}-\mathrm{H}$ bond energy of the $\alpha$-position. However, the inductive effect of this electronegative substituent deactivates the hydrogens in other positions since the halogen atoms are electrophilic. Therefore, the further the position is removed from the substituent, the more reactive it is. These two factors are observed in gas phase free-radical chlorination ${ }^{2}$ and bromination $^{2}$ of alkyl halides. For example, the gas phase chlorinations of butane, 1-chlorobutane, and 2-chlorobutane' (Table I) show deact1vation of the $\beta$-position. The gas phase brominations of electronegatively

\section{Table I}

Relative reactivities in gas phase chlorination at $35^{\circ}$

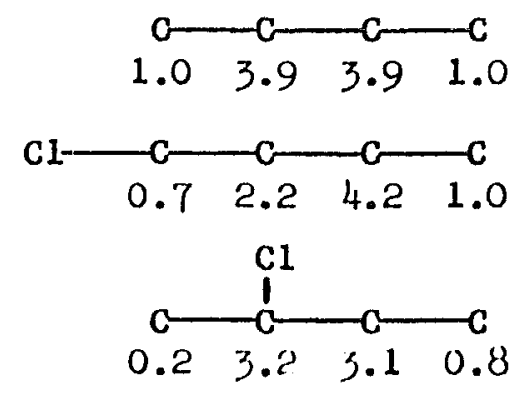


substitutad 1-butanes also glve minor aubstitutiono at $\beta$-carbon (Table II). ${ }^{3}$ The reactivity of the $\alpha$-position depanda on the combination of

Table II

Selectivities in gas phase bromination at $160^{\circ}$

$\begin{array}{crrrrr} & \alpha & \beta & \gamma & 6 \\ \times & 0 & 0 & 0 & C \\ \mathrm{CF}_{3} & 1 & 7 & 90 & 1 \\ \mathrm{~F} & 9 & 7 & 90 & 1 \\ \mathrm{CH}_{3} \mathrm{OCO} & 19 & 29 & 73 & 1\end{array}$

these two competing factors, the polar effect and the lower $\mathrm{C}-\mathrm{H}$ bond energy. The $\beta$ and $\gamma$ positions are both secondary and should have the nearly equal $\mathrm{C}-\mathrm{H}$ bond strength. Thus, the ratio of relative reactivities of $\beta$ and $\gamma$ hydrogens 18 used to measure the polar effect.

In Ifquid phase halogenation, Thaler ${ }^{4}$ observed the same results for chlorination and bromination of 1-chlorobutane and chlorination of 1-bromobutane (Table III). However, he also observed that

Table III

Relative reactivities in liquid phase halogenation of 1-halobutane at $60^{\circ}$

Butyl chloride

$$
\mathrm{XCH}_{2}-\mathrm{CH}_{2}-\mathrm{CH}_{2}-\mathrm{CH}_{3}
$$

$\begin{array}{lllll}\mathrm{Cl}_{2} & 0.158 & 0.478 & 1.00 & 0.397 \\ \mathrm{Br}_{2} & 0.439 & 0.488 & 1.00 & \ldots . . .\end{array}$

Buty 1 bromide

$\begin{array}{lllll}\mathrm{Cl}_{2} & 0.093 & 0.434 & 1.00 & 0.455 \\ \mathrm{Br}_{2} & 0.062 & 5.78 & 1.00 & \ldots . .\end{array}$

1,2-dibromobutane is the major product in bromination of 1-bromobutane (Table III). The reactivity at carbon-'? was ').78 tines that of carbon-q. 
Bromination of bromocyclohexane gave $94 \%$ of trans-1,2-dibromocyclohexane, whlle the bromination of chlorocyclohexane gave only about $10 \%$ of the vicinal dihalide. A simflar result vas found for bromination of bromocyclopentane, which gave $90 \%$ of trans-1,2-d1bromocyclopentane. LikeHise, the radical bromination of 2-bromobutane gave $84 \%$ of $2,3-$ dibromobutane, while the bromlnation of 2-chlorobutane gave only $8 \%$ of the 2,3-dihalide. Thaler interpreted thls activation of the $\beta$-position in bromination of alkyl bromides in termb of nefghboring group participation (anchimeric aosiotance), which was well-documented ${ }^{5}$ in carbocationic reactions but unprecedented in radical reactions. *

The rate determining step for these radical reactiong is the hydrogen abstraction step. The larger and more polarizable bromide substituent can assist this $\beta$-hydrogen abstraction more effectively than can chlorine. ${ }^{\dagger}$ Hydrogen abstraction by chlorine atom shows little selectivity and has little bond brealing at the transition state. There 1s little chance for anchimeric assistance to occur. In contrast, abstraction by bromine atom, with greater bond breaking, would involve the neighboring substituent, which would delocalize the unpaired electron and lower the energy of transition state (1). In keeping with this expectation, the major product is vincinal dibromide.

\footnotetext{
* The concept of bridging and anchimeric assistance was proposed in 1952 for radical reactions, ${ }^{6}$ however, these proposals were retracted later. ${ }^{\dagger}$ Chlorine participation was also reported by Traynham and Hinea.'
} 


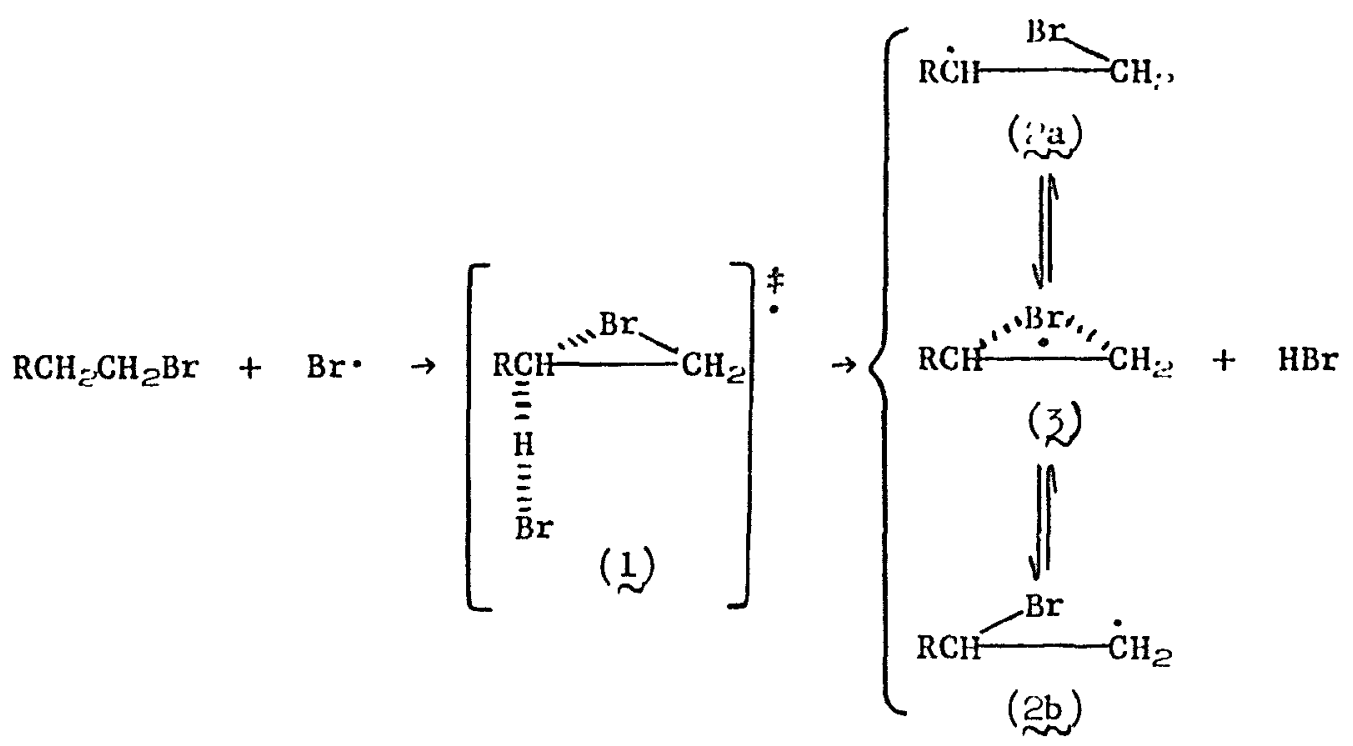

(2) and/or (立) $+\mathrm{Br}_{2} \rightarrow \mathrm{RCHBrCH}_{2} \mathrm{Br}+\mathrm{Br}$.

The bromo substituent participates in forming a bridged transition state ( $\underset{\sim}{1})$; however, this bridging does not dictate the structure of the intermediate $\beta$-bromoalkyl radical as a bridged ( 2 ) or nonbridged (2) species. Since the rate determining step is the hydrogen abstraction step, and if there is no reversal reaction, the analysis of the product distribution serves to indicate the relative reactivities of different hydrogens. Thus, the observation of 1,2 -dibromide as major product, contrasting with the expected polar effect of the substituent, indicates anchimeric assistance.

However, the reversibility of the reactions of atomic bromine with alkanes is well-documented. $8-10$ To avold the possibility of this reversibility of alkyl radical and hydrogen bromide, bromostasis has been used for the bromination. Bromostasis is a method for carrying out a bromine substitution reaction at constant bromine concentration. The reaction of $\underline{N}$-bromosuccinimide (NBS) with hydrogen bromide is found to be instantaneous.11,12 Thus, the hydrogen bromide that is generated by abstraction of hydrogen by bromine atom caul be scavenged by NBS, and broinine 18 regeneruled. By thls means, one cun 
avold the posstbllity of $\mathrm{HBr}$ reversal. Recently, Skell, et al., reported 12,23 results obtalned from the competition photobromination of a gertes of halogenated alkanes ya. their unsubstituted analogo under bromostasis conditions. In all cases, the bromoalkanes were substituted faster than their corresponding alkanea. The Investigators proposed that neighboring bromine asgisted In the transiticn state for hydrogen abstraction by the bromine atom.

Similarly, Traynham and $H_{1} e^{7}$ reported that the radical monobromination of 1-bromomethy 1-4-methylcyclohexane with bromine gave exclusively substitution at the position $\beta$ to the bromine substituent (eq 3).<smiles>CC1CCC(CBr)(CBr)CC1</smiles>

Lewis and Kozulcal4 observed that the Lootope effects in the radical addition of $\mathrm{HBr}(\mathrm{Or} \mathrm{TBr}$ ) to a sertes of terminal olefins are small and show no maximum (Table IV). If the intermediate radical is a classical Table IV

Isotope effect in the radical addition of $\mathrm{HBr}$ to $\mathrm{RCH}=\mathrm{CH}_{2}$ at $\mathrm{O}^{\circ}$

\begin{tabular}{|c|c|}
\hline $\mathrm{R}$ & $\mathrm{k}_{\mathrm{H}} / \mathrm{k}_{\mathrm{T}}$ \\
\hline $\mathrm{p}^{-T o 1 y 1}$ & $1.04,1.03$ \\
\hline Pheny 1 & $1.46,1.47$ \\
\hline $\mathrm{p}^{-C h l o r o p h e n y l}$ & $1.55,1.62$ \\
\hline tert-Buty 1 & $1.99,1.99$ \\
\hline n-Hexy 1 & $2.07,2.07$ \\
\hline $\mathrm{Br}$ & 2.83 \\
\hline $\mathrm{H}$ & $4.14,4.25$ \\
\hline
\end{tabular}


radical, then the $R=$ pheny 1 should give the maximum isotope effect, and the magnitude is calculated to be $49.1,-3.2\left(v_{\mathrm{H}}^{\ddagger}=0-1200 \mathrm{~cm}^{-1}\right)$ at $0^{\circ}$ by use of Melander's equation. ${ }^{I ' j}$ The benzyllc carbon-hydrogen bond and the $\mathrm{HBr}$ bond have about the same energies (ca. $87 \mathrm{Kcal} / \mathrm{mole}$ ) ${ }^{13}$ therefore, the cases of $R=$ ary 1 would appear to be those with the least zero-polnt stretching vibration. The observation that the isotope effect of $R=$ phenyl is not a maximum, and as little as 1.46 can be explained by the participation of the $\beta$-bromine, which stabilizes the radicals and weakens the $\mathrm{C}-\mathrm{H}$ bond. Thus, the maximum in the isotope effect will not come at $R=$ aryl, but should come farther down the table (Table IV).

The anchimeric assistance requires a trans arrangement of hydrogen and bromine. For example, the bromination of 1someric 4-tertbutylcyclohexyl bromides would give a mixture of dibromides if there were no neighboring group assistance. Substitution should occur at varlous positions and decrease in the order of $4>3>1>2$ for both tsomers. However, this prediction was not fulfilled in the bromination of c1s-4-tert-butylcyclohexyl bromide, which yielded a single product, trans-1,2-dibromo-c1s-4-tert-butylcyclohexane (Eq 4).17 Photobromination

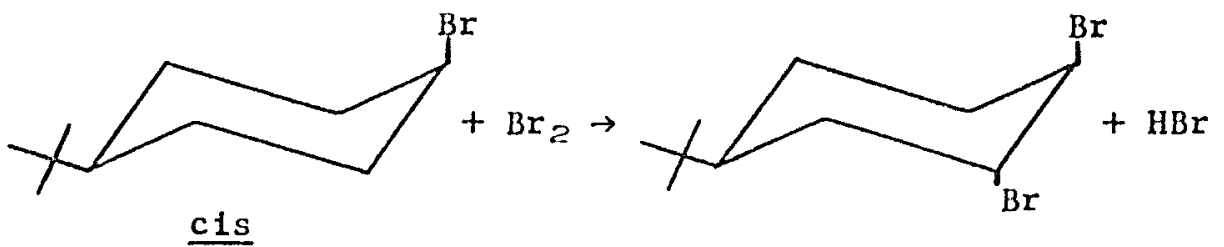

of the trans-1somer gave a mixture of dibromides. Further, the competitive photobromination showed the c1s-18cmer to be $\geq 15$ more reactive than the trans-1somer. These different results can be explained by the trans arrangement of bromine and hydrogen in the more stable chair form for the c1s-1somer ( $\underset{\sim}{4}$ ) but only in the less stable boat form for the trans-isomer (5). Competitive photobrominations of c18-4-tert-butylcyclohexyl bromide 

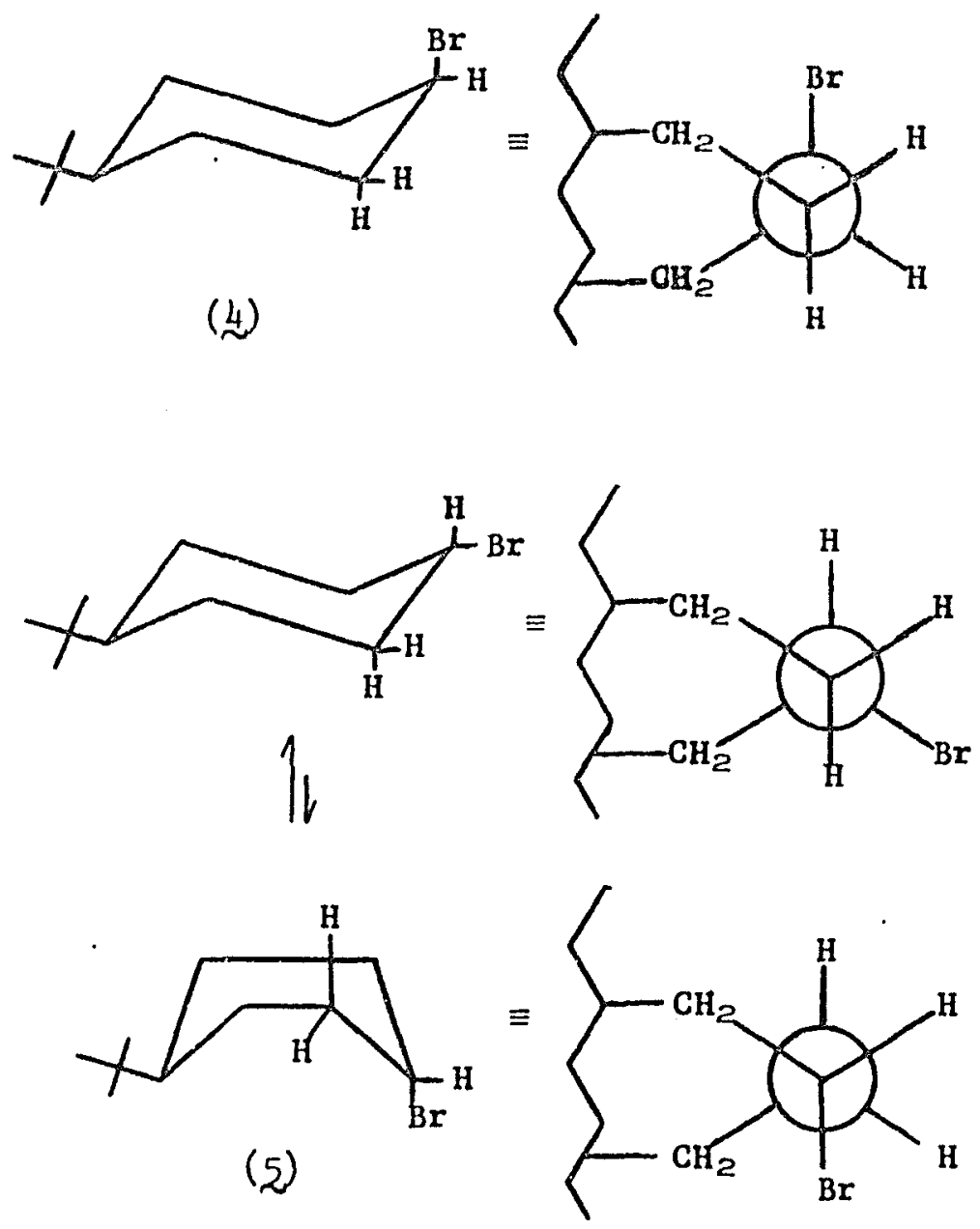

ve. cyclohexane showed 1045 fold anchimertc assistance. 12 This increase was attributed to the locked-in configuration ideal for neighboring group to participation. The small anchimeric effect, 26 fold, was observed in substitution of the $\beta$-hydrogen in butyl bromide; the anchimeric effect was consldered operable only in the less stable conformation (6). 12<smiles>CC1C(Br)C2CCC1C(Br)C2</smiles>

Et<smiles>[Z17]C1CC2CCC1C(C)C2CCC</smiles>

H

(0) 
Iuyser and Feng ${ }^{1 E 1}$ reported that a threo $\beta$-substituted alcohol, 3-bromo-2-butanol, reacted faster with tert-butoxy radical than did the erychro foomer (Table V). With chlorine as substituent, the foomeric

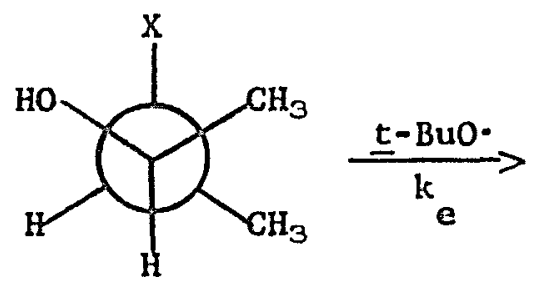



erythro<smiles>[X]C1C(C)C2CCC1(C)C(C)C2O</smiles><smiles>CC1(C)[R8]CCC1</smiles>

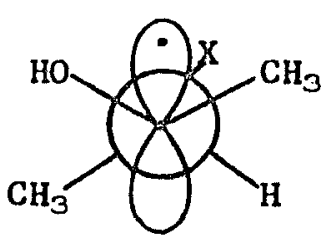

threo

\section{Table V}

Competition reactions of stereolsomeric 3-halo- and 3-methylthio-2-butanols

\begin{tabular}{|c|c|}
\hline $\mathrm{X}$ & $k_{t} / k_{e}$ \\
\hline $\mathrm{Cl}$ & 1.02 \\
\hline $\mathrm{Br}$ & 1.44 \\
\hline $\mathrm{SCH}_{3}$ & $1.20^{\circ}$ \\
\hline
\end{tabular}

alcohols were about equal in reactivity. The greater relative reactivity of the threo isomer with a bromine substituent was attributed to a preferred conformation in the transition state to permit the $\beta$-bromine particlpation. The erythro 1somer would have eclipsed methyl groups in a transition state involving bridging.

The observation of anchimeric assistance does not indicate that the structure of the intermediate will be a bridged (D) or nonbridged (8) spectes. The C-C bond can rotate in nonbridged radical, and the trapping agent can approach from either side of the trivalent carbon atom. In 

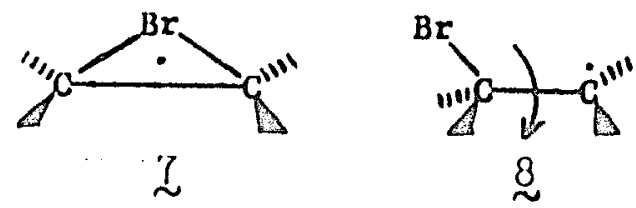

contrast, the bridged structure correlates with a large barrier to rotation about the C-C bond, and the trapping agent has to approach to the back-side of $\mathrm{Br}$. Although much evidence has been found for the bridged Intermsdiate, ${ }^{17,19-21}$ such evidence does not bear directly on the question of anchimeric assistance in the hydrogen abstraction step of alkane brominations. Because the existence of the intermediate is of some interest here, however, I shall cite three examples of the evidence for 1llustration. First, Ske11, et al., observed different rat108 of meso/d,스 dibromides by photolnitiated bromination of 2-bromobutane, erythro-3-2H-2bromobutane, and threo-3-2h-2-bromobutane under bromostasis cond1tions (Table VI).2I If a classical open chain radical were the intermediate, Tabie VII

$$
\begin{aligned}
& \text { Ratio of diastereomeric 2;3-dibromobutanes from the } \\
& \text { photobromination of } 2 \text {-bromobutanes } \\
& \text { Starting materlal } \\
& \text { mean/d, } 1 \\
& \begin{array}{ll}
\text { 2-bromobutane } & 2.5 \\
\text { erythro- }\left(3-{ }^{2} H\right)-2 \text {-bromobutane } & 0.61 \\
\hline \text { threo- }\left(3-{ }^{2} H\right)-2 \text {-bromobutane } & 6.50
\end{array}
\end{aligned}
$$

the same meoo/d, $\underline{1}$ ratio should be obtalned for each of the compounds. The large variation in this ratio observed indicates that there are more than a single intermediate in the reaction. The variation in product ratio can be explained with two isomeric bridged intermediates, (2) and (10), formed

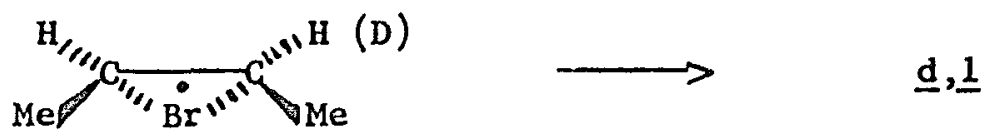

(2)<smiles>C[C@H]1[C@@H]2[C@@H](C)[C@@H](C)[C@@H]12</smiles>



(10) 
in different ratios as a result of the different reactivities of $H$ and D In the abstraction step (Eqg 5 and 6).<smiles>[2H]C1CC2CC(C1C)C(C)C2C</smiles>
exythro<smiles>[2H]C1C2CCCC(C2C)C1(C)Br</smiles>

threo<smiles>[2H]C1C(Br)C2CCC1C(C)(Br)C2Br</smiles>
$\underline{d}, \underline{1}-D_{1}$<smiles>[2H]C1C2C(Br)C(Br)C(C)(C1C)C2Br</smiles>
meso- $\mathrm{D}_{1}$

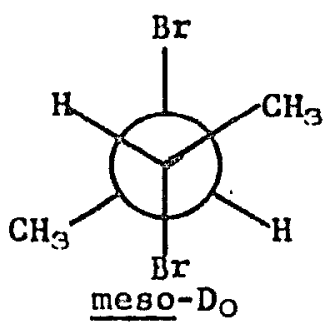<smiles>CC1C(Br)C2CCC1(C)C(Br)C2Br</smiles>

$\underline{\mathrm{d}}, \underline{1}-\mathrm{D}_{\mathrm{O}}$

Second, bromination of 3-bromopentane- $82_{\mathrm{Br}}$ with ordinary bromine by bromostasis produced a mixture of erythro- and threo-2,3dibromopentanes ( $\mathrm{Eq} \mathrm{7).21} \mathrm{Dehydrobromination} \mathrm{by} \mathrm{base} \mathrm{of} \mathrm{the} \mathrm{threo-}$<smiles>CCC(Br)Br</smiles><smiles>[H][R17]1(C)CC[Nb]1</smiles>

$82_{\mathrm{Br}}$<smiles>CCC1C(Br)C2CCCC1C2(C)C</smiles>

threo

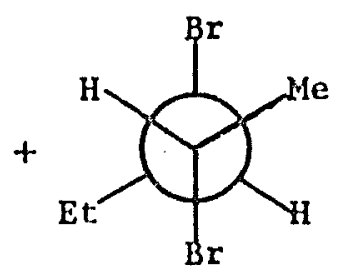

erythro

$$
\mathrm{RMA}=0.94 \quad \mathrm{RMA}=1.00
$$

$\mathrm{RMA}=$ relative molar radioactivity: (counts/mmole)/(counts/mmole) $s t d$

dibromide obtained from above bromination reveals that the original radioactive bromine atom is evenly distributed between the 2- and 3-positions (Eq 8).21 (The bromoolefins obtained from dehydrobromination of the

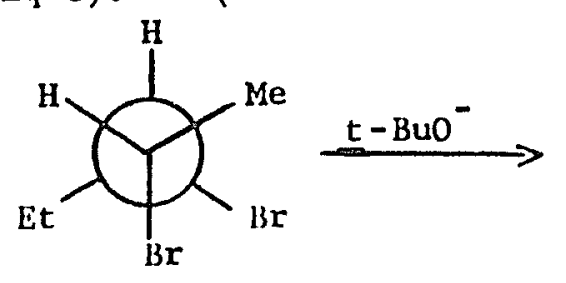

threo<smiles>CCCC(CC)=C(C)C(CC)=C(C)C</smiles> 
exythro diastereomer could not be separated.) These results aloo ouggest the bitdged intermedlate for the bromination of 3-bromopentane. Other evidence for control of stereochemistry by nelghboring bromine to cited in a review by skell and shea. 22

Lyons and Symons 23 studled the esr opectrum of $\beta$-bromoalky' radicals and concluded that the radical existed in a locked conformation with the bromine atom in the plane of the unpaired electron orbital.

\section{B. Evidence against bridging by neighboring bromine in Free-radical reactions}

As the evidence accumulated to glve Indications that anchimeric assistance does exist, the contrary argument also developed. Central to the controversy is the mechanism of bromination by NBS, for some of the proposals 24 that speak againot anchimeric assistance are supported almost solely by the presumed sameness of bromination mechanism for both molecular bromine and NBS reagents.

NBS has been recognized as an effective allylic (and benzylic) bromination agent without addition to double bond since ziegler, et al. 25 first reported the reaction. In $1944, H^{28}$ and $B$ loomfleld ${ }^{27}$ suggested a radical mechanism for NBS bromination. Bloomfleld also proposed the succinimidyl radical as the allylic hydrogen abstractor, and NBS as the bromlne transfer spectes (Eqs 9 and 10). This "Bloomfield mechantsm"

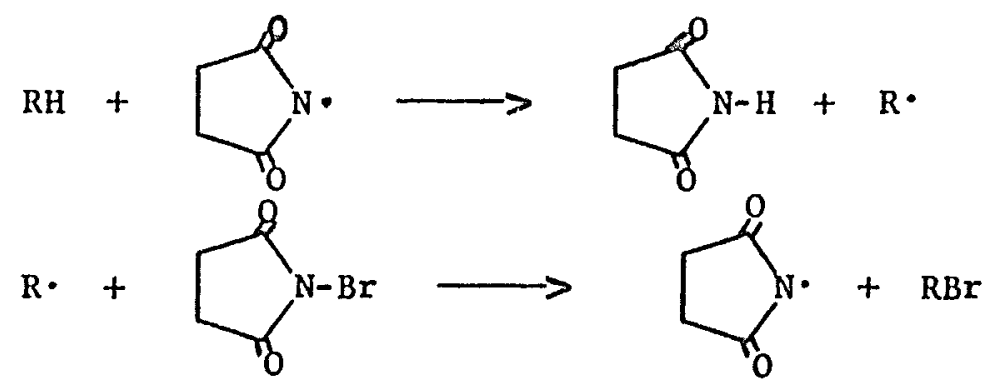


gained popular acceptance for 20 years. However, Goldfinger, et al. ,28 proposed that NBS behaves like $\underline{N}$-chlorosuccinimide, which was proved to serve as a source of $\mathrm{Cl}_{2}$ in low concentration. Bromine atoms, which were made possible by the presence of a trace of bromine in the reaction system, were suggested to be the hydrogen-abstracting apecion instead of succinfmidyl radicals. NBS supplies a low steady-state concentration of bromine by reaction with hydrogen bromide (Eq 13). To explain the

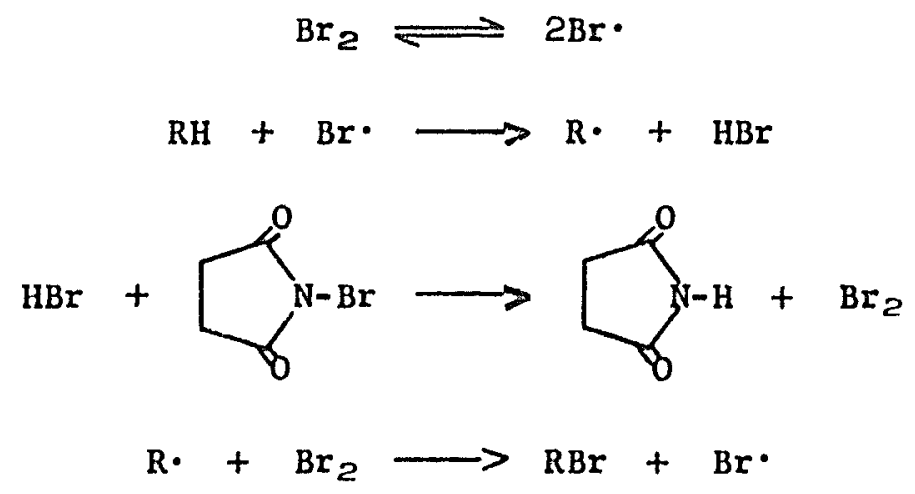

specificity for allylic substitution, Goldfinger proposed that the abstraction of allylic hydrogen by bromine atom is irreversible bcaause the hydrogen bromide generated 1s immediately scavenged by NBS, but the addition of bromine atom to double bond is reverstble. At very low concentration of bromine in the system, the rate of reverse of $\beta$-bromoalkyl radical back to olefin and bromine atom is faster than the trapping of $\beta$-bromoalkyl radical by bromine. With these bases, it is easy to understand why allylic bromination is observed in bromination by NBS. This "Goldfinger mechantam" became more popular than the "Bloomfleld mechan1sm" because of several items of evidence outlined below. Sixma and Reim 29 observed that photobromination by the slow introduction of bromine into a refluxing solution of cyclohexene in carbon tetrachloride ylelded $84 \%$ of 3-bromocyclohexene. McGrath and 
Tedder 30 observed not only the allylic substitution with low concentration of bromine but also the indirect ovidence for the reverse of $\beta$ bromoalkyl radical back to olefin and bromine atom by obtaining a rapld Isomerization of c1g-3-hexene to the trang 1somer during the reaction of the olefin with NBS.

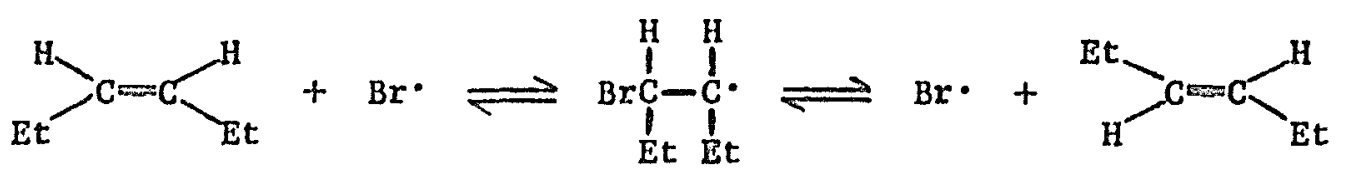

Sixms and Retmi2 also observed the same relative reactivity for the competitive bromination of toluene and $p^{-n i t r o t o l u e n e}$ with both brominating reagents $\left(\mathrm{Br}_{2}\right.$ and $\left.\mathrm{NBS}\right)$. Wherg ${ }^{8}$ observed essentially the same deuterfum isotope effect in bromination of toluene and toluene- $\alpha$ ${ }^{2} \mathrm{H}_{3}$ with both brominating reagents. These results of same reactivity and same kinetic 1sotope effect also suggested the same hydrogen abstraction species.

Kooyman, et al. ${ }^{31}$ reported that bromination of substituted toluenes using bromine and NBS at $80^{\circ}$ gave $\rho$ values of -1.05 and -1.55 , respectively. Therefore, both reactions could not be proceeding by the same mechanism. However, Pearson and Martin ${ }^{32}$ observed identical $\rho$ values $\left(-1.36\right.$ at $80^{\circ},-1.76$ at $\left.19^{\circ}\right)$ for both bromine and NBS. They also demonstrated that $\mathrm{HBr}$ was responsible for the different $\rho$ values obtalned by Kooyman. Kooyman's $\rho=-1.05$ could be duplicated at lower rat los of $\mathrm{Br}_{2} / \mathrm{HBr}$ and hence was being perturbed by reversibility of the abstraction step. Walling, et al., 10 also observed that the relative reactivities of substituted toluenes toward NBS correlated well with $\sigma^{+}$and ylelded $\rho=-1.38$. Th1s value agrees well with the value obtained by Pearson and Martin. 
Identical reactivities for benzylic hydrogens with bromine and NBS have been demonstrated by the data of aralkyl hydrocarbons reported by Russe1133 and Walling. ${ }^{30}$ This Identity led to the conclusion of the same mechaniom for bromine and NBS.

Even though the quantitative data which I have discussed do not give any indication of succinimidyl radical participation in the NBS bromination chain, the authors cited were careful to say that the conclusion of the same mechantsm for bromine and NBS applied to benzylic or allylic aystems only. Chemlsts generally seem to have extended the identity to all systems. For example, Poutsma sa1d: "From an exper1mental point of view, it now seems that a good method of measuring bromine atom selectivities is the use of NBS to avold reversal of abatraction."34 An 1llustration of such an extension to alkanic hydrogen has been reported by Tanner, et al. 24

Tanner and coworkers have challenged the 1dea of kinetic assistance by the neighboring bromo substituent in the hydrogenabstraction step. They relnvestigated the photobromination of 1bromobutane with molecular bromine 4 and reported that the product mixtures formed consisted mainly of 1,3-dibromobutane at less than $18 \%$ conversion, and that the ratio of 1,2 to 1,3 -dibromides increased with the extent of the reaction (Table VII), unt 11 the final product mixture consisted of $88 \% 1,2$-dibromobutane. $24 \mathrm{a}$ Therefore, they argued that the apparent activating effect of the bromo substituent must be attributed to a difference in the rate of reaction of a bromoalkyl radical with $\mathrm{HBr}$ and with bromine at positions vicinal to and more remote from the bromo substituent in the bromoalkyl radical. As bromination proceeded, $\mathrm{HBr}$ accumulated in the mixture, and the reversal of the radical-forming step 
Table VII

Isomer distribution for the bromination of butyl bromide with molecular bromine at $40^{\circ}$

\begin{tabular}{|c|c|c|c|c|}
\hline Reaction & \multicolumn{2}{|c|}{ Dibromobutaneo } & \multicolumn{2}{|c|}{ distribution } \\
\hline \% & 1,1 & 1,2 & 1,3 & 1,4 \\
\hline 2 & 0.52 & 0.53 & 1.00 & \\
\hline 18 & 0.43 & 0.67 & 1.00 & \\
\hline 29 & 0.26 & 1.10 & 1.00 & \\
\hline 95 & Trace & $7 \cdot 30$ & 1.00 & \\
\hline
\end{tabular}

(Eq 16) was presumed to be faster than the reaction of alkyl radical

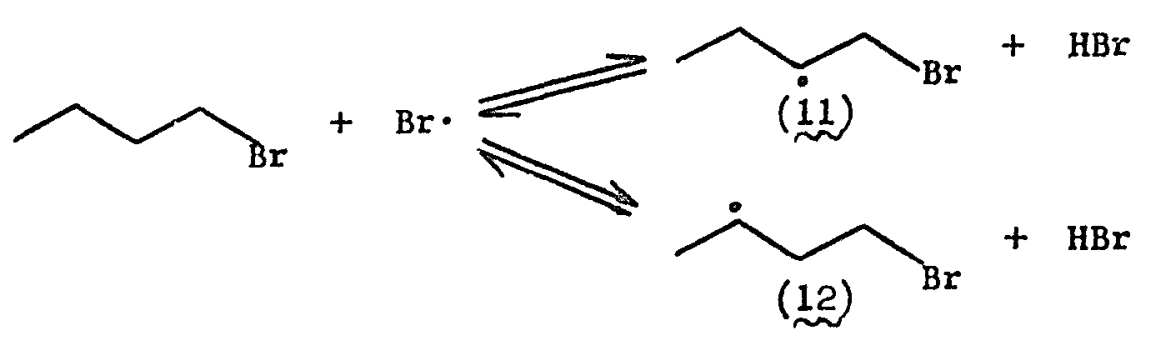

with bromine. Also, the reversal of (12) is faster than that of (11) because (11) 18 more polar and is expected to react slower with the polar agent HBr. They also proposed that in the NBS reaction, NBS would remove the $\mathrm{HBr}$ formed, allowing the reaction to give malnly the kinetically controlled product, 1,3-dibromobutane. However, they falled to obtain trana-1,2-d1bromocyclohexane as a minor product in the bromination of cyclohexyl bromide by molecular bromine, even at $1.3 \%$ converston. $24 b$ In other words, the $\mathrm{HBr}$ effect on the bromine reaction of butyl bromide could not be obtained with the cyclohexyl bromide system. Nevertheless, these authors still considered the NBS reaction data to be the true data for kinetic control in the bromine reaction, since the NBS reaction could give a minimum of interference from the reversible reaction of the alkyl radicals and the hydrogen bromide produced. They observed that trans-1,2-dibromocyclohexane (no c1s 1somer detected) was the minor 
product for the reaction at 1838 than $64 \%$ conversion in the AIBN-initiated NBS reaction. Therefore, they concluded that no evidence of anchimeric: assistance by the neighboring bromine atom could be found (Table VIII).

Table VIII

Isomer distribution for AIBN Initiated bromination of bromocyclohexane with NBS

\begin{tabular}{|c|c|c|c|c|c|c|}
\hline $\begin{array}{c}\text { Reaction } \\
\frac{o}{p} \\
\end{array}$ & 1,1 & trans 1,2 & $\begin{array}{l}\text { trans } 1,3 \\
\end{array}$ & $\begin{array}{l}\text { rat } 10 \cdots- \\
\text { c1s } 1,4\end{array}$ & c1s 1,3 & trans 1,4 \\
\hline 2 & 0.51 & 0.22 & 1.0 & 0.72 & 0.71 & 0.50 \\
\hline 64 & 0.50 & 0.97 & 1.0 & 0.60 & 0.71 & 0.60 \\
\hline 84 & 0.55 & 1.2 .1 & 1.0 & 0.62 & 0.71 & 0.54 \\
\hline 96 & 0.46 & 1.57 & 1.0 & 0.62 & 0.70 & 0.60 \\
\hline
\end{tabular}

After part ${ }^{35}$ of the work of this Dissertation and related work by others ${ }^{1: 3}$ were published, Tanner and coworkers retracted the ir early report that at $18 \%$ or less reaction the 1,3 -ditromobutane is the major product from bromination of butyl bromide. $24 \mathrm{~d}$ In this same article as the retraction, the interpretation of the slow reaction of $\beta$-bromoalkyl radical with hydrogen bromide persists, now based on new data reported for reactions in 1 iquid bromine solvent.

Experimentally, Tanner and coauthors sald, $24 \mathrm{~d}$ the reversal of $\mathrm{HBr}$ with alkyl radical can be made noncompetitive by two means: remove $\mathrm{HBr}$ by NBS; (2) carry out the bromination with a large excess of bromine so that essentially all the alkyl radicals produced can be trapped by molecular bromine.

Tanner, et al. ${ }^{24 d}$ observed that the different relative rates of brominations of a number of alkanes and substituted alksnes with bromine and NBS disappeared when the brominations with bromine were carried out in 11quid bromine solvent (Table IX). 
Table IX

Competitive brominations of butyl bromide and cyclohesane

$R_{2} H$
butyl

Bromination agents and conditions

NBS

$$
\mathrm{R}_{1} \mathrm{H}: \mathrm{R}_{2} \mathrm{H}: \mathrm{Br}_{2}=1: 1: 100
$$

$$
\mathrm{k}_{\mathrm{R}} \mathrm{H}^{\prime} \mathrm{k}_{\mathrm{n}} \mathrm{H}
$$$$
0.58 \pm 0.10
$$

$0.52 \pm 0.02$

The purpose of this work was to resolve the controversy over bridging by a neighboring bromine in the transition state for freeradical hydrogen abstraction, and to investigate the possibility of different mechantsms for radical brominations of alkanic positions by bromine and by NBS. The photobrominations of butyl bromine 4,240 were reinvestigated. Some earlier data in the literature on bromocyclohexane halogenation $24 b$ indicated that the isomer distribution obtained with NBS reagent is closer to that obtained with chlorine than to that with bromine. We began to suspect that with alkanic hydrogen, bromine and NBS might be reacting by different mechanisms, involving different hydrogenabstracting radicals with different selectivities. Competitive reaction data were used to establish the identity of bromine and NBS mechanisms for benzylic systems. Therefore, we investigated the competitive reactions, butyl bromide vs. cyclohexane and cyclopentane vs. cyclohexane. We also investigated the reactions with single substrates, cyclopropane and norbornane, which can form in particularly informative ways different products by competitive processes. 


\section{RESULTS AND DISCUSSION}

The deactiveting polar effect of a chloro substituent toward radical halogenation of an alkyl chain 18 well-establishod. 30 when the 11quid-phase bromination of alkyl bromides (Including butyl bromide and cyclohexyl bromide) led to the formation predominantly ( $85 \%$ or more) of vicinal dibromides, these contracting results were taken as strong evidence for kinetic assistance by the nelghboring bromo substituent in the hydrogen-abstraction step. However, Tanner and coworkers proposed that the selective $\mathrm{HBr}$ reversal was responsible for the preferential formation of 1,2 -dibromides by molecular brcmine because 1 was strongly and directly tied to the observation of the predominant formation of nonvicinal dibromides at less than $18 \%$ reaction of butyl bromide with bromine and in the radical reactions of NBS with butyl bromide and with cyclohexyl bromide. 24 The hydrogen-abstracting agent was assumed to be the same $(\mathrm{Br} \cdot)$ in both the molecular bromine and the liBS reactions, and the NBS was presumed to consume $\mathrm{HBr}$ as rapidly as it was generated. In our laboratory, we tried to reproduce Tanner's results of 1,3-dibromobutane as major product with less than $18 \%$ reaction of butyl bromide with bromine. In spite of repeated, meticulous efforts, we could not reproduce these results. We obtalned the 1,2 -dibromobutane as major product for extents of reaction ranging from less than $1 \%$ to $100 \%$.

If Tanner's $\mathrm{HBr}$ reversal theory ts correct, then the reversal of bromoalkyl radical with $\mathrm{HBr}$ has to be faster than the trapping of bromoalky 1 radical by bromine. Although the separate kinetic data do not appear to be avallable, for other alkyl and haloalkyl radicals for 
which data are reported, "The rate of reaction of alkyl radical with bromine is considerably more rapld than the corresponding reaction with HBr."137 Our results of fallure to obtaln 1,3-dibromobutane as the major product, even early in the reaction with little HBr generated, speak strongly against the HBr reversal proposal. The brominations of buty 1 bromide were run at $4 \pm 1^{\circ}, 25 \pm 1^{\circ}$, and $60.7 \pm 1.5^{\circ}$ and the results are sumarlzed in Table $x$. The product ratto of 1,2 -d1bromobutane

Table $\mathrm{X}$

Isomeric product distributions obtained from brominations of butyl bromide with molecular bromine.

\begin{tabular}{|c|c|c|c|c|c|}
\hline $\begin{array}{l}\text { Time } \\
\text { min. }\end{array}$ & \multicolumn{4}{|c|}{$\begin{array}{l}\text { Rel amounts of } \\
\text { Isomeric dibromobutanes }\end{array}$} & Av \\
\hline \multicolumn{6}{|c|}{  } \\
\hline $\begin{array}{r}2 \\
4 \\
8 \\
16 \\
32 \\
64 \\
128\end{array}$ & $\begin{array}{c}1.37 \\
2.95 \\
6.41 \\
10.5 \\
22.1 \\
43.5 \\
75.4\end{array}$ & $\begin{array}{l}0.1 \\
0.1 \\
0.1 \\
0.1 \\
0.1\end{array}$ & $\begin{array}{l}7.3 \\
7.3 \\
7.6 \\
7.5 \\
7.3 \\
7.3 \\
8.9\end{array}$ & $\begin{array}{l}1.0 \\
1.0 \\
1.0 \\
1.0 \\
1.0 \\
1.0 \\
1.0\end{array}$ & $\begin{array}{l}1.1 \\
2.1 \\
1.5 \\
1.4 \\
1.3 \\
0.98 \\
1.2\end{array}$ \\
\hline \multicolumn{6}{|c|}{ - $60.7 \pm 1.5^{\circ} ; \mathrm{BuBr}: \mathrm{Br}_{2}=7.5: 1^{\mathrm{C}} \ldots$} \\
\hline $\begin{array}{r}1 \\
3 \\
10 \\
25 \\
40\end{array}$ & $\begin{array}{l}1.74 \\
22.5 \\
71.5 \\
89.8 \\
99.8\end{array}$ & $\begin{array}{l}0.1 \\
0.09 \\
0.10 \\
0.11 \\
0.11\end{array}$ & $\begin{array}{l}4.5 \\
4.5 \\
5.2 \\
5.7 \\
6.1\end{array}$ & $\begin{array}{l}1.0 \\
1.0 \\
1.0 \\
1.0 \mathrm{~b} \\
1.0\end{array}$ & $\begin{array}{l}2.0 \\
2.4 \\
0.65 \\
0.94 \\
1.1\end{array}$ \\
\hline \multicolumn{6}{|c|}{ - $11^{\circ} ; \mathrm{BuBr}: \mathrm{Br} r_{2}=5.9: 1^{\mathrm{c}}$} \\
\hline $\begin{array}{r}4 \\
10 \\
25 \\
63\end{array}$ & $\begin{array}{r}1.01 \\
2.12 \\
3.42 \\
13.05\end{array}$ & $\begin{array}{l}0.1 \\
0.1 \\
0.1 \\
0.1\end{array}$ & $\begin{array}{l}11 \\
11 \\
11 \\
11\end{array}$ & $\begin{array}{l}1.0 \\
1.0 \\
1.0 \\
1.0\end{array}$ & $\begin{array}{l}0.39 \\
0.52 \\
1.5 \\
1.6\end{array}$ \\
\hline
\end{tabular}

a. Each Iine of data is the average from two to three gc injections; the average deviations are given in the last column. b. The distribution in this line, equivalent to the ratios $1,1: 1,2: 1,3=1.4: 84.7: 13.9$, is nearly identical, within the deviation limits specified, to that reported by Thaler. c. Mol ratio of reactants. 
to 1,3-dibromide remains the same for reactions up to approximately $50 \%$ conversion. In reactions of higher conversions, the $1,2 / 1,3$ rat 10 Increases slightly, but not to the extent reported at first by Tanner.24a No 1,4-dibromobutane was detected in any of these product mixtures. The $60.7 \pm 1.5^{\circ}$ reaction gave the identical product diatribution as that reported by Thaler 4 in 1963 within the experimental error. The product ratios of 1,2-dibromobutane to 1,3-d1bromobutane decreased as the temperature 1ncreased. Th1s agrees with the early report ${ }^{38}$ that the chlorInation of alkyl chlorides at highex temperature glves progressively less vicinal product with increasing temperature. This phenomenon is called the "vicinal effect" and has been attributed to the Instability of $\beta$-chloroalkyl radicals in high temperature. The data in Table $\mathrm{X}$ show the same trend and are attributed to the instability of $\beta$-bromo radical derived from butyl bromide and less nelghboring bromine assistance at the higher temperature.

Tanner's data for photoinftlated bromination of butyl bromide with NBS in acetonitrile show no 1,4 -dibromobutane in the product $\mathrm{m} 1 \mathrm{x}-$ ture throughout the course of reaction $24 a$ (Table XI); however, the data

Table XI

Isomer distribution in the photoinftiated bromination of butyl bromide with NBS in acetonitrile

Total ylelds of dibromides, \%

$$
5.5
$$

22.6

23.4

105.0

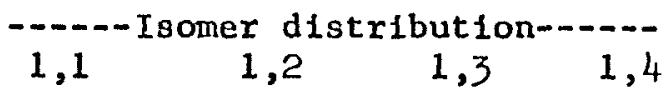

0.19

0.24

0.21

Trace
0.29

0.95

1.15

5.51
1.00

1.00

1.00

1.00

for the similar reaction initlated with azoisobutyronitrile (AIBN) indicate 1,4 -dibromobutane as a product in reaction mixture after $51 \%$ 
conversion $24 b$ (Table $X I I$ ). The authors did not provide any reason for this varlation. Our date obtained from photoinftiated NBS bromination

Table XII

Ieomer distribution in the AIBN-initiated bromination of butyl bromide with NBS in acetonitrile

$\underset{\%}{\operatorname{Reaction}}$

9

37

51

55

57



$0.27 \quad 0.30 \quad 1.00$

$0.28 \quad 0.84 \quad 1.00$

0.34

1.36

1.00

1.25

1.00

1.37

1.00

0.08

0.33

0.08

of buty1 bromide in acetonitrile show 1,4-dibromobutane is the product In the reaction mixture throughout the reaction (Table XIII). These

Table XIII

Isomeric product distributions obtained from photolnttiated NBS bromination of butyl bromide in acetonitrile at $60 \pm 1^{\circ}$ (Mo1 ratio $\mathrm{NBS}: \mathrm{BuBr}: \mathrm{CH}_{3} \mathrm{CN}=1: 5.9: 27$ )

$\begin{array}{rccccc}\text { Time, } & \text { \% NBS } & -- \text { Rel } & \text { amounts of } & \text { isomeric dibromides- } \\ \text { Min. } & \text { consumed } & 1,1 & 1,2 & 1,3 & 1,4 \\ 4 & 5.4 & 0.29 & 0.30 & 1.0 & 0.17 \\ 30 & 35.7 & 0.27 & 0.53 & 1.0 & 0.12 \\ 62 & 58.1 & 0.24 & 0.89 & 1.0 & 0.08 \\ 105 & 80.5 & 0.20 & 1.16 & 1.0 & 0.06 \\ 165 & 93.5 & 0.20 & 1.10 & 1.0 & 0.06 \\ 230 & 95.9 & 0.23 & 1.13 & 1.0 & 0.06\end{array}$

data are very different from those obtained in reaction with molecular bromine. Even in the reaction with $96 \%$ conversion of NBS, the $1,2 / 1,3$ ratio is only 1.13 , as compared with a value of 6.1 obtalned from the reaction with molecular bromine after $99.8 \%$ conversion. 
Tanner, et al, also obtalned different product distribution from cyclohexyl bromide and NBS with photoinitiation and with AIBN initiation. $2 a b$ They reported that a bromine color developed during the more rapid photoinitiated reaction and suggested that a portion of the bromination was attributable to utilization of the molecular bromine. Since the color developed early when plenty of NBS was avallable for reaction with $\mathrm{HBr}$ - a reaction reported to be near-1nstantaneous 11,12 this explanation seems tantamount to acknowledging different selectivities and different attacking radicals for the NBS and bromine reactions. These data were published in $1972^{35}$ along with those of another group who also reported that 1,2-dibromobutane is the mafor product.13 Tanner, et al., 2Ad later published another paper in which they retracted their early report that at $18 \%$ or 1 ess reaction the 1,3 -dibromobutane was the major product. In that same article, however, the HBr reversal theory remains, based now on new data reported for some competitive reactions in liquid bromine solvent. The authors suggested that essentially all of the alkyl radicals generated could be trapped by molecular bromine by carrying out the bromination with a large excess of bromine. However, an alkyl bromide alone probably provides, by internal competition, a better test of the importance of hydrogen bromide reversal than does the competition between different substrates in bromine solvent. With butyl bromide, the ratio $1,2-\mathrm{C}_{4} \mathrm{H}_{8} \mathrm{Br}_{2}: 1,3-\mathrm{C}_{4} \mathrm{H}_{8} \mathrm{Br} \mathrm{r}_{2}$, did not decrease when we changed from $0.1 \mathrm{~mol}$ equivalent of bromine to $100 \mathrm{~mol}$ equivalent of bromine and Interrupted the reaction after less than $3 \%$ of the butyl bromide reactant had been converted. Polybromination does not occur under these conditions. Were hydrogen bromide reversal Important and faster with less polar radicals (bromo substituent more remote from radical center) 
than with more polar ones, ${ }^{24}$ and were excess bromine able to override that reaction as claimed, 24d higher proportions of 1,3-dibromobutane would be expected with large excesses of bromine than with 0.1 mol equiv. Since we do not obtain that result, hydrogen bromide reversal must play little or no role in the proportions of dibromobutanes formed." Therefore, we believe that the interpretation 24 of the butyl bromide-bromine reaction which emphasizes reversal of the Inttial allcyl radical formation 18 erroneous and that the earlier interpretation ${ }^{4}$ in terms of kinetic assistance by neighboring bromine is supported by the present data.

Some earlier data in the literature on bromocyclohexane halogenations $24 b$ indicate that the 1somer distribution obtained with NBS reagent is cloger to that obtained with chlorine than to that with bromine. High selectivity by the attacking radical (substantial bond breaking and radical character development in the transition state) is essential for neighboring bromine participation. If the attacking radical in NBS brominations of alkanes is not bromine atom and is lower In selectivity than is bromine atom, the difference in product distributions for NBS and bromine brominations of alkyl bromides is comprehensible, and the apparent relevance of the NBS reactions to the actual

\footnotetext{
By private communication, Professor P. S. Skell and J. C. Day (Pennsylvania State Unfversity) have informed us that they have confirmed these observations with butyl bromide, and have extended the Investigation to 1-bromoheptane, which likewlse gives essentially unvarying proportions of (five) 1someric dibromoheptanes over widely differing substrate: bromine ratios $(10: 1$ to $1: 100)$, with and without NBS present.
} 
mechanism of molecular bromine brominations 18 lost. Therefore, several alkanic systems were selected for study because of their potential for revealing the Identity or difference in mechaniom for the two brominating reagents. The results of these studies are summarized and discussed in the following, sections.

Butyl bromide vg. cyclohexane. An equin.olar mixture of butyl bromide and cyclohexane was brominated with a 0.1 mol equiv of molecular bromine or of NBS. With bromine, the product ratio was approsimately 11 times the ratio obtained with NBS. Butyl bromide reacts faster than cyclohexane with bromine $\left(\mathrm{BuBr}: \mathrm{C}_{{ }^{\circ}} \mathrm{H}_{22}=2.3: 1\right)$, but slower than cyclohexane with NBS (BuBr: $\left.\mathrm{C}_{\mathrm{Q}} \mathrm{H}_{12}=0.20: 1\right)$. With both reagents, the dibromobutane 1somer distribution was the same as that obtalned under the same conditions with butyl bromide substrate alone.

The intermediate radicals, $\dot{\mathrm{C}}_{4} \mathrm{H}_{8} \mathrm{Br}$ and $\mathrm{C}_{8} \mathrm{H}_{1}{ }^{\circ}$, are formed by competitive hydrogen abstractions and react competitively with the source of substituent bromine. If reversal of the hydrogen abstraction Is unimportant, the product ratio, $\mathrm{C}_{4} \mathrm{H}_{8} \mathrm{Br}_{2}: \mathrm{C}_{6} \mathrm{H}_{21} \mathrm{Br}$, is concordant with the relative rates of hydrogen absiraction from the two substrates. The reversal reaction may occur to substantially different extents with the two intermediate radicals, however, because of the posstbility of unfavorable interactions between the bromobutyl radical (more polar than the unsubstituted cyclohexyl radical) and polar HBr. ${ }^{24 d}$ ThIs kind of difference in reaction of radical intermediates with $\mathrm{HBr}$ would lead to a bromination product which indicates a higher relative rate of substitution into butyl bromide than that which would be indicated in the absence of $\mathrm{HBr}$ reversal. Thus, the difference in relative rates of bromfuat Lon of the two substrates by molecular bromine and by Nisi is 
consistent with different mechanisms but, in the absence of other data, Is not compelling evidence for them.

I find that Irradiation of an equimolar butyl bromidecyclohexane mixture in a large excess (100 mol equiv) of bromine does produce a product mixture indicative of a subatantially increaged relative reactivity of cyclohexane $\left(\mathrm{C}_{4} \mathrm{H}_{3} \mathrm{Br}: \mathrm{C}_{8} \mathrm{H}_{12}=1: 3.1\right.$ at $\left.60^{\circ}\right)$. Some trans-1,2-dibromocyclohexane 18 also formed (no 1somers detected), and the dibromobutane 1somer distribution is the same as that obtained with 0.1 mole-equivalent of bromine.

I cannot now account to my own satisfaction for the fact that the change from a brominating mixture which is largely hydrocarbon to one which is largely bromine changes cyclohexane from a less reactive to a more reactive competitor with butyl bromide. One reasonable rationalization 1 les in the possible complexation of bromine atom with bromine molecule $\left(\mathrm{Br}_{3}{ }^{\circ}\right)$, similar to the well-known anion, $\mathrm{Br}_{3}^{-}$. Chlorine atom complexes with aromatic solvents to give radicals different In reactivity from $\mathrm{Cl} \cdot{ }^{38 a}$ It may be that $\mathrm{Br}_{3} \cdot$ is the chain-carrying species in bromine solvent and has reactivicy-selectivity quite different from $\mathrm{Br}^{*}$ (or $\mathrm{Br}$ - complexes with $\mathrm{RBr}$ ). We have no data to support (or refute) this proposal. The overall results, however, (viz., cyclohexyl bromide faster than cyclohexane, and the essentially unchanged dibromide 1somer distribution) do not fit or gupport the interpretation 24 dhat selective hydrogen bromide reversal (reduced or eliminated in excess bromine) is enhancing the apparent reactivity of the alkyl bromide with respect to the cyclohexane.

\section{Cyclohexane y8. cyclopentane, Cyclohexane and cyclopentane} undergo chlorinations at different relative rates $\left(k_{C_{5}} H_{10} / k_{C_{6}} H_{12}=\right.$ 
0.85 at $\left.68^{\circ}\right) .39$ In radical brominations, these two substrates yield Intermediate cycloalkyl radicalo, boch of which are unsubstituted and are expected to show little if any difference in reactivity toward $\mathrm{HBr}$. Competitive brominations of this pair of hydrocarbons at $60^{\circ}$ with moleculax bromine give relative reactivity ratios of $\mathrm{C}_{5} \mathrm{H}_{10}: \mathrm{C}_{6} \mathrm{H}_{12}=6.8$

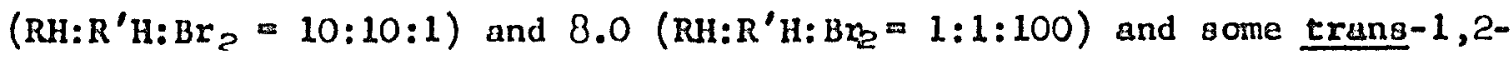
dibromocyclopentane; with NBS the relative reactivity ratio 181.6 , and dibromlde is formed. The change from hydrocarbon to bromine solvent does affect the $\mathrm{C}_{5} \mathrm{H}_{20}: \mathrm{C}_{\theta_{0}} \mathrm{H}_{12}$ reactivity ratio slightly, but the change is an Increase; the ratio 18 clearly not reduced 24 do that obtained with NBS.

The similarity of the chlorination rates was attributed to the small extent of bond breaking at the transition state (small extent of eclipsing strain relief). ${ }^{39}$ The substantially different rates for bromination by molecular bromine are consistent with the greater extent of bond breaking expected at the transition state for hydrogen abstraction by $\mathrm{Br}^{\cdot}$ than by $\mathrm{Cl} \cdot$. It is difficult to rationalize these data with any mechanism which specifles that the hydrogen-abstracting spectes 18 the same for $\mathrm{Br}_{2}$ and NBS reagents.

Cyclopropane. Cyclopropane undergoes 11quid phase radical halogenations to give substitution product (cyclopropyl halide) and ring-opening product (1,3-dihalopropane). The proportions of these competitively-formed products depend on the 1dentity of the halogenation reagent. With chlorine as reagent ( $\mathrm{Cl} \cdot \mathrm{cha1n})$, the ratto of cyclopropy 1 chloride:1,3-dichloropropane is about $1: 4$ at $0^{\circ}$ and about $1.5: 1$ at $68^{\circ} .40$ With tert-butyl hypochlorite (ㄷ-Buo. cha1n) however, the 
ratto is at least $17: 1$ at both $0^{\circ}$ and $68^{\circ} .40$ In an early study which eotablished the radical character of the reaction between cyclopropane and bromine $(\mathrm{Br} \cdot \operatorname{chaln}), 1,3$-dtbromopropane, the only product identifled, was obtalned in high yield. 42 Under the same conditions, hydrogen bromide ( $\mathrm{Br} \cdot$ chain) also gave only ring-opening product (propyl bromide). 11 It is clear and unsurprlsing that different radical reagents $(\mathrm{Cl} \cdot \underline{\mathrm{t}}-\mathrm{Bu} \cdot \cdot \text {, and } \mathrm{Br} \cdot)^{\prime}$ glve quite differing proportions of hydrogen abstraction and ring-opening processes with cyclopropane.

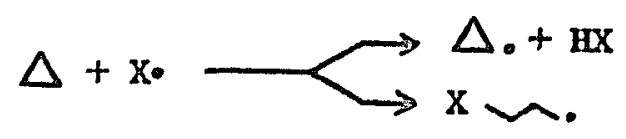

When we carried out photoinitiated brominations of cyclopropane $\left(\mathrm{C}_{3} \mathrm{H}_{8}: \mathrm{Br}_{2}=10: 1 \mathrm{~mol}\right.$ ratio) in methylene chloride solution at $0^{\circ}$, only 1,3-dibromopropane was obtalned; no cyclopropyl bromide was detected by gas chromatography. (There was no reaction under these conditions in the dark). Even with an irradiated solution of cyclopropane in 1iquid bromine (approximately $0.1 \mathrm{~mol}$ equiv of $\mathrm{C}_{3} \mathrm{H}_{6}$ ), 1,3-dibromopropane was the sole product detected. When we used NBS $\left(C_{3} H_{B}\right.$ :NBS $=10: 1$ mol ratio) In acetonitrile solution, however, $>98 \%$ of the product mixture was cyclopropyl bromide. These completely opposite ratios of products from $\mathrm{Br}_{2}$ and NBS reactions must mean that different chain-carrying radicals (Br* and presumably succinimidyl) are generated from the two reagents. 
One $(\mathrm{Br} \cdot)$ reacts exclusively by attack on carbon (to give ringopening), but the other, 11ke tert-butoxy radical, abstracts hydrogen predominantly. The relative energles of the alternative palrs of bonds formed and broken (X-C/C-C vs. $\mathrm{X}-\mathrm{H} / \mathrm{H}-\mathrm{C}$ ) undoubtedly determine the alternative pathways for reaction, ${ }^{*}$ but the data required for a "prediction" when $X=$ succinimidyl are not avallable to us.

Norbornane. Norbornane undergoes chlorination with a variety of chlorinating reagents to give malnly a mixture of exoand endo-2-chloronorbornanes whose composition is dependent on the identity of the chlorine-transfer agent which reacts with the 2 -norbornyl radical intermediate. 42 Although the exo/endo ratio is related to the size of the chlorine transfer reagent, the order of probable steric requirements of these reagents does not coincide with the order of exo/endo ratios.

\footnotetext{
* The difference of bond energies between $\mathrm{C}-\mathrm{Br}$ and $\mathrm{C}-\mathrm{I}$ in methy 1 halides is $13.7 \mathrm{Kcal} / \mathrm{mole}{ }^{16}$ Benson $41 \mathrm{a}$ has estimated the activation energy for the ring opening by lodine atom as $17.5 \mathrm{Kcal} / \mathrm{mole}$. Therefore, the activation energy for ring opening by bromine atom may be about $3.8 \mathrm{Kcal} / \mathrm{mole}$. The bond energy for $\mathrm{C}-\mathrm{H}$ in methane 18104 $\mathrm{Kcal} / \mathrm{mole}$ and that in cyclopropane is $101 \mathrm{Kcal} / \mathrm{mole}{ }^{10}$ Since the activation energy for hydrogen abstraction from methane by bromine atom is $18.3 \mathrm{Kcal} / m o l e, 16$ the activation energy for hydrogen abstraction by bromine atom in cyclopropane may be about $15.3 \mathrm{Kcal} / \mathrm{mole}$. Therefore, the preference for cyclopropane ring opening over hydrogen abstraction by bromine atom is readily apparent.
} 


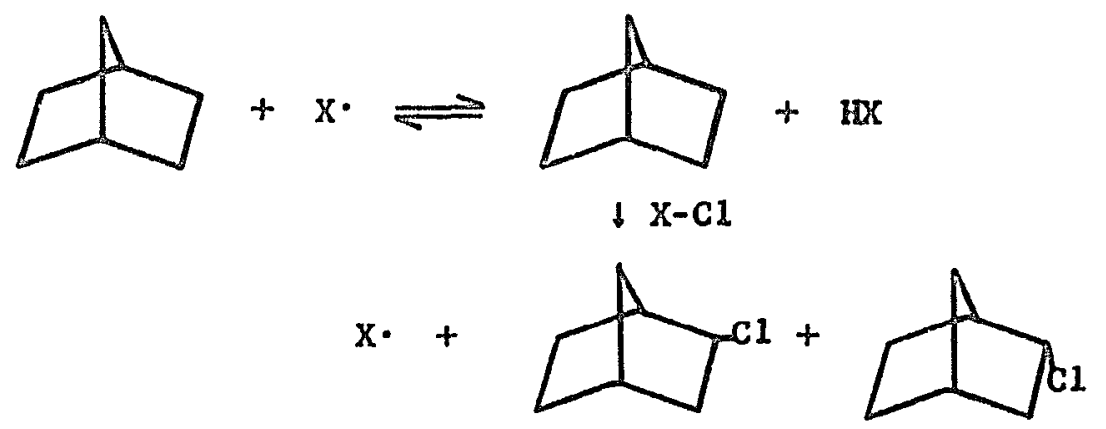

The important aspect for our present consideration, however, is that the exo/endo ratio is different for different halogen-transfer reagents


how substantial or little is the reversal reaction with $\mathrm{HBr}$, it is difflcult to see how that reaction can have any effect on the exo/endo product ratio obtalned from brominations. If the bromine-transfer species are the same, the same stereolsomeric product ratio will be obtained. Conversely, if different exo/endo product ratios are obtained with different brominating reagents, the bromine-transfer species must be different.

Kooyman and Vegter 139 reported the bromlnation of norbornane with bromine in bolling carbon tetrachloride $\left(80^{\circ}\right)$ gave an exo/endo product ratio of 3 (only the exo product was actually determined), that use of $\mathrm{BrCCl}_{3}$ (AIBN Inftiation) gave an exo/endo product ratio of 5.3 and the use of NBS (AIBN Initiation) gave a low conversion to impure product for which an exo/endo ratio could not be determined. When photo-brominating norbornane with molecular bromine (0.14 mol equiv in Freon 113 solution), no 1-bromonorbornane was detected in the product mixture, and the exo/endo ratio of 2-bromonorbornanes was 2.1. When I used NBS as brominating reagent $(0.1$; mol equiv In methylene dichloride solution), some 1-bromonorbornane ( $8.0 \%$ ) was 
found in the product mixture, and the exo/endo rat1o of 2-bromonorbornanes was 3.7. Then 2-bromonorbornane was prepared by the koch1 reac$\operatorname{tion}^{43}$ (2-norbornanecarboxylic ac1d, lead tetrancetace, oodium bromlde), the exo/endo of 2-bromonorbornanes formed from the 2-norbornyl radical Intermediate was 1.8 .

With bromine, a small amount of a mixture of loomeric dibromides was formed, along with the monobromides, but the product distrio bution pattern ( $\mathrm{gc}$ ) was quite different from that obtained by reaction of bromine with norbornene. 44 I did not attempt to determine the absolute or even relative ylelds of all these 1someric dibromonorbornanes, because such data would have required a substantial amount of experimental work that would have made no contribution to the 1ssue of bromine vg. NBS mechanisms. It seems rather certaln then that these dibromides are formed by radical substitution into the monobromides rather than by an $\mathrm{HBr}$ elimination- $\mathrm{Br}_{2}$ addition sequence. When a mixture of 2-bromonorbornanes ( $\underline{\text { exo }} / \underline{\text { endo }}=1.8)$ was brominated with $\mathrm{Br}_{2}(0.067$ mol equiv), the bromine was consumed faster than it was with norbornane under the same conditions, and the same mixture of dibromides was formed. The exo/endo ratio of reactants remained constant, however, within the precision of the gc measurements, throughout the course of the bromination. Thus, the exo/endo product ratio obtained from norbornane and $\mathrm{Br}_{2}$ is reliable and unaffected by the small amount of dibromination which occurred.

These results establish that brominations of norbornane by $\mathrm{Br}_{2}$ and by NBS Involve different bromine-transfer species, different mechanisms. I believe that the original reagent is the bromine-transfer agent with both molecular bromine and NBS and that all available information favors this conclusion for other alkanic systems. 
Discusston. The oingle publication that attacks the mechantom of alkanic bromination by NBS seems to be that by skell, et al. 45 They observed that a 500-fold change in concentration of NBS for bromination

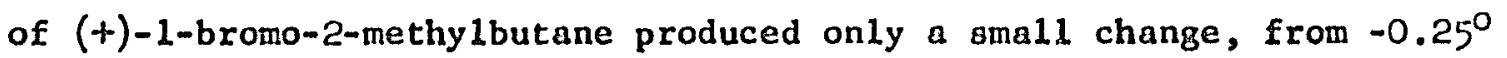
to $-0.30^{\circ}$, in the rotation of the final product (Table XIV). Th1s leads Table XI

$\begin{array}{lccc}\text { Bromination of }(+)-1-\text { bromo-2-methylbutane by NBS } \\ \text { Solvent } & \begin{array}{c}\text { Temp., } \\ \left({ }^{\circ} \mathrm{C}\right)\end{array} & \begin{array}{l}\text { Solubllity of } \\ \text { NBS (mol/1) }\end{array} & \begin{array}{c}\alpha_{\text {obsd }} \\ \text { (temp., }{ }^{\circ} \mathrm{C} \text { ) }\end{array} \\ \mathrm{CFCl}_{3} & 25 & 0.0006 & -0.25(28) \\ \mathrm{CH}_{2} \mathrm{Cl}_{3} & 40 & 0.29 & -0.30(25) \\ \mathrm{CCl}_{4} & 76 & 0.006 & -0.06(35)\end{array}$

to the conclusion that "the alkyl radical intermediate 1 s not brominated by NBS, but presumably by molecular bromine present in steady low concentration." These authors attributed the low optical rotation $\left(-0.06^{\circ}\right)$ In carbon tetrachloride solvent (concentration of NBS 10 times higher than $\mathrm{In}_{,} \mathrm{CFCl}_{3}$ ) to the effect of temperature, also observed in the reaction of (t)-1-bromo-2-methylbutane with molecular bromine (Table XV).19

Table XV

Bromination of $(+)-1$-bromo-2-methylbutane by bromine

$\begin{array}{cc}\text { Temp. }\left({ }^{\circ} \mathrm{C}\right) & \alpha_{\text {obsd }}\left(27^{\circ} \mathrm{C}\right) \\ -40 \text { and }+40 & -2.86^{\circ} \\ 72-80 & -2.33^{\circ}\end{array}$

This explanation assumes that both NBS and bromine reactions have the same mechantsm and therefore the same temperature effect, even though the temperature effect observed for the bromine reaction is much smaller than that for NBS reaction. This greater dependence of the $\alpha$ value on temperature change in the NBS reaction compared with that in the bromine 
reaction may suggest that NBS is actually the bromine transfer species. Because NBS is a positive halogen compound (13), the transfer of bromtne



(13)

to an alkyl radical should be slower than from molecular bromine. Therefore, the lifetime of the radical intermediate for the NBS reaction is longer, and more racemlzation can be observed. A larger temperature effect might be expected for the longer intermodiate lifetime, thus a larger increasing racemtzation could be obtalned by changing the temperature from $25^{\circ}$ to $76^{\circ}$, even though the concentration of NBS was increased 10 times. Had the 500-fold concentration of NBS (methylene chloride solution) been run at $25^{\circ}$ instead of $40^{\circ}$, the $\alpha$ value may have been larger than $-0.30^{\circ}$. In other words, a temperature effect may exist in the NBS reaction for a change from $25^{\circ}$ to $40^{\circ}$, although no temperature effect has been found for the bromine reaction over this temperature range. Therefore, an increase in the $\alpha$ value expected for a 500-fold increase in NBS concentration may be partially cancelled by the temperature effect. It is hard to distinguish between Skell's proposal and this explanation by the results reported in Tables XIV and XV without further experiments.

A group of French workers ${ }^{48}$ reported the isolation of sizable quantities of adducts of olefins with NBS. One might consider this addition of NBS to olefins as an Ionic reaction. However, Zalkow and Kennedy 47 observed that NBS reacted (benzoyl peroxide Initiation) with 
bicyclo[2.2.1]hept-5-ene-endo-c1s-2,3-dLcarboxyl1c anhydride in carbon tetrachloride to give exo-5-bromo-exo-6-succinimidobicyc1o[2.2.1.]heptane-endo-c1s-2,3-dicarboxyl1c anhydride (14). Th1s exo-c1s addition

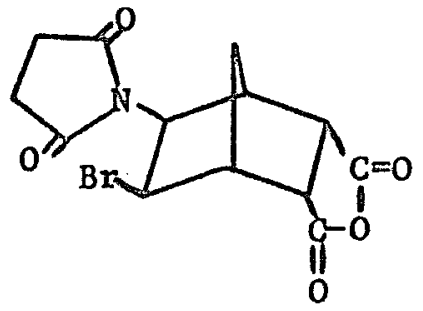

$(\stackrel{14}{\sim})$

of NBS to the double bond appears to rule out the possibllity of addition by an Ionic mechanism, because Ionic reaction would be expected to give a trans adduct by way of an intermediate bridged bromonium ion. The by-product of this reaction is $\beta$-bromopropionyl 1socyanate.

The rearrangement of NBS to $\beta$-bromoproplonyl 1socyanate was f1rst observed 1ndependently by Johnson and Bubll1tz $z^{48}$ and Bartlett and Martin. 49 The rearrangement proceeds by $\beta$-scission of succinimidy 1 radical. The observation of this rearrangement strongly suggests that, during a bromination by NBS, succintmidyl radical may be present.

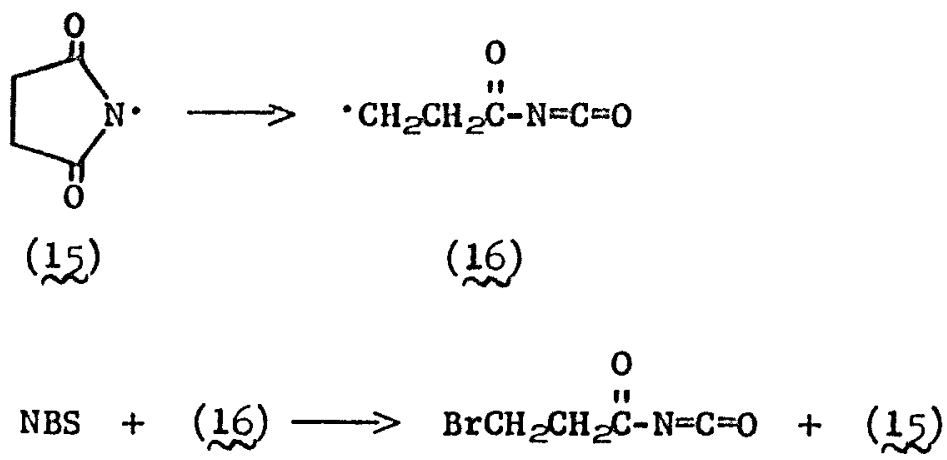

Tanner, et al., tried to show that the reactivity observed in the NBS reactions was not due to a carbon-centered radical $[(16)$, arising from $\beta$-scission of a succinimidyl radical ] by comparing the NBS reactivity 
with that of three other $\underline{N}$-bromo amides, viz., 1,3-dibromo-5,5dimethylhydanto in (17), 1-bromo-3,5,5-trimethylhydantoin (18), and tetramethyl-N-bromosuccinimide (12). They concluded that all four Nbromo brominating agents showed the same reactivity, even though a three-fold range of reactivities was actually reported (Table XVI) 24d

Table XVI

Relative rates of competitive brominations of chlorocyclohexane $\left(\mathrm{R}_{1} \mathrm{H}\right)$ and cyclohexane $\left(\mathrm{R}_{2} \mathrm{H}\right)$

Brominating

$(15)$

NBS

(16)

(17)

$$
\begin{aligned}
& \frac{k_{R_{2} H} / k_{R_{2}}}{0.43 \pm 0.01} \\
& 0.23 \pm 0.02 \\
& 0.18 \pm 0.02 \\
& 0.14 \pm 0.02
\end{aligned}
$$

for the chlorocyclohexane:cyclohexane competition (the one for which the data are most precise). Contrary to their claim that bromine atoms are the hydrogen abstractors in each case, the data actually support a

\begin{tabular}{|c|c|}
\hline $\begin{array}{l}\text { Brominating } \\
\text { agent }\end{array}$ & 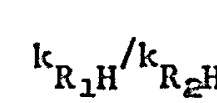 \\
\hline NBS & 15.8 \\
\hline$(\underset{\sim}{20})$ & $11 \pm 4.5$ \\
\hline (21) & 8.44 \\
\hline (22) & $6.2 \pm 0$ \\
\hline
\end{tabular}
proposal that difierent chain carrying species are involved. Earlier, Walling and Rieger50 obtained "quite simllar" relative reactivities (Table XVII) for NBS and three other N-bromo amides [V1z., 1-bromo-5-

Table XVII

1 sobuty1-5-methylhydanto in ( 20$), 3$-bromo-1,5,5-trimethylhydanto in (21), 
and 1-bromo-s,5,5-trimethylhydantoln $\underset{\sim}{22})]$ reacting competitively with ethylbenzene and toluene. The published data, however, do show as big as a 2.5-fold range. Agaln, the data may support a proposal that four different imidyl radicals, four different chaln carrying species, are obtained from different N-bromo amides. These authors also reported", the relative reactivities toward alkanic positions vs. toluene (Table XVIII). From the data, they concluded: "Data Table XVIII

Relative rates of alkanic posttions vs. toluene toward $\underline{\mathrm{N}}$-bromo amides

\begin{tabular}{|c|c|c|}
\hline Substrate & NBS & (20) \\
\hline Toluene & 1.00 & 1.00 \\
\hline 2,3-D 1methylbutane & 0.07 & 0.10 \\
\hline Methy lcyclohexane & 0.027 & 0.06 \\
\hline$\underline{n}$-Octane & 0.022 & 0.017 \\
\hline Cyclohexane & 0.012 & 0.017 \\
\hline
\end{tabular}

for saturated hydrocarbons are subject to considerable uncertainty and may represent merely orders of magnitude. In any case, the results again support the hypothesis of a common bromine atom chain as the major reaction path." In my opinion, the data equally strongly suggest that bromine atoms are not the common hydrogen-abstraction spectes for NBS and (20).

Our data for competitive reactants and for two single substrates, which were brominated by molecular bromine and by NBS, demonstrate that radical brominations of alkanic positions by bromine and by NBS proceed by different mechanisms. Yet the evidence that vhe same mechanism (Br* cha1n) occurs with benzylic positions ${ }^{*}$ is equally

*NBS bromination of ethylbenzene was investigated; the gc spectrum showed a trace amount of $\beta$-bromoethylbenzene, which could not be detected by nmr 
compelling. "11,:":, $: 3:$ a How can we reconclle these results?

The transition state for hydrogen abstraction by a hromfine aloun involves considerably more bond-breaking (and a higher activation energy) than the one for hydrogen abstraction by chlorine atom. 51 The reactivity ratio for toluene:cyclohexane at $80^{\circ}$ is 60 for bromination but 0.091 for chlorination. ${ }^{51}$ For bromination, but not for chlorination, the C-H bond breaking with toluene is sufficient to allow substantial stabilization of the transition state by benzylic resonance, compared with the alkanic system, cyclohexane. The electronic effect of gem-phenyl actually slows hydrogen abstraction by chlorine atom. NBS dissoctation can potentially inftiate either a bromine atom or succinimidyl radical chain. With alkanic systems (at least the<smiles></smiles>

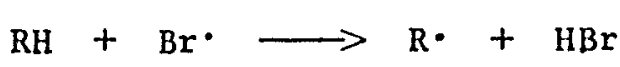<smiles>CCCC1NC(=O)CCC1=O</smiles><smiles>O=C1CCC(=O)N1</smiles>
$\mathrm{Br}{ }^{*}$

$$
\begin{aligned}
& \mathrm{R} \cdot+\mathrm{Br}_{2} \longrightarrow \mathrm{RBr}+\mathrm{Br} \cdot \\
& \mathrm{Br}_{2} \rightleftharpoons \mathrm{Br}
\end{aligned}
$$

spectroscopy. This trace amount of $\beta$-bromoethylbenzene suggested that the succinimidyl radicals at least competed with bromine atoms for hydrogen abstraction. 




ones we have examined, without exception), the succinimidyl chain appears to have the lower activation energy and is the one which occurs. The selectivity patterns indicate that, as with Cl-, little C-H bond breaking has occurred at the transition state for succinimidyl attack, and 1 ittle resonance stablization of the transition state from benzylic systems is to be expected. As is true for chlorine atom, then, succinimidyl radical will, we belleve, react less readily with benzylic systems than with alkanic ones. With benzylic systems, the alternate, bromine atom chain becomes favored, because of stablilzation in the transition state.

Photodissoctation of NBS under our conditions (tungsten lamp) Is far slower and less efficient than is photodissociation of bromine. Therefore, in mixtures containing both bromine and NBS, bromine atom generation will far exceed succinimidyl radical generation. These mixtures give alkanic product distributions substantially the same as those obtained with bromine alone rather than those obtained with NBS alone. ${ }^{35}$ In a mixture of bromine and NBS, the bromine atom chain does not diminish the concentration of bromine nor the efficiency of generation of bromine atoms. 


\section{EXPERTMENTAL}

\section{A. General}

All small glass ampoules used for bromination roactions were cleaned first with cleaning solution, second with concentrated aqueous ammonia. They were then rinsed with distilled water and dried in an oven.

The reagents used in all syntheses were reagent grade commerclal chemicals. They were used wthout further treatment unless otherwise Indicated.

Ultraviolet (uv) spectra and visible (vis) spectra were obtained with a Cary 14 recording spectrophotometer. Infrared (1r) spectra were obtained with a Perkin-Elmer 137 infrared spectrophotometer Liquid samples were examined as thin film on sodium chloride plates. Proton nuclear magnetic resonance ( $\mathrm{nmr}$ ) spectra were obtained with a Varian Assoclates Model A60A, or a Perkin-Elmer R12 nuclear magnetic resonance spectrometer. Samples were examined as 10-20\% solution in carbon tetrachloride with tetramethylsilane (TMS) as internal reference. Chemical shifts are reported relative to TMS in $\delta$ units, and coupling constants are recorded in Hertz $(\mathrm{Hz})$. The following abbreviations are used to describe the splitting patters: 3 singlet, $d=$ doublet, $t=$ triplet, and $\mathrm{m}=$ multiplet.

Gas chromatographic (gc) data were obtalned with a HewlettPackard Model 700 Instrument equipped with a hydrogen flame Ionization detector and 0.125 in., Teflon-1 ined aluminum columns packed with $10 \%$ Carbowax $20 \mathrm{M}$ or $10 \%$ QF-1 on $60 / 80$ mesh Chromosorb 2 (acid washed). Preparative ge separations were accomplished with a Varian Aerograph 
Model 90-P instrument equipped with a $5 \mathrm{ft}$. $x 0.25$ in. column packed with 10\% Carbowax $20 \mathrm{M}$ on $60 / 80$ mesh Chromosorb $W$ (ac1d rashed).

\section{B. Syntheses}

\section{Preparation of 1 1-dibromobutane}

1,1-D1bromobutane was obtalned by a Hungdiecker degradation from 2-bromopentanolc acid by a described procedure. 52

\section{a. 2-Bromopentanoic actd53}

Pentanolc acid ( $115 \mathrm{~g}, 1.08$ moles) and red phosphorus powder (4.5 8) were placed in a 250-ml 3-necked flask equipped with a thermometer, a reflux condenser carrying a gas exit through a calclum chloridetube, an addition funnel having a pressure-equalizing side arm, and a magnetic stirring bar. Bromine ( $180 \mathrm{~g}, 1.1$ moles) was dropped slowly from the addition funnel into the reaction mixture whereby the temperature rose to $60^{\circ}$. Hydrogen bromide gas was generated profusely and was trapped with $3 \underline{M}$ sodium hydroxide solution. When the addition of bromine was completed, the flask was heated with a heating mantle to keep the temperature at $65^{\circ}$. More hydrogen bromide was 11berated while the brown bromine color of the mixture slowly lightened. After 3 hours, the escape of hydrogen bromide stopped. Excess bromine was removed under aspirator suction at $65^{\circ}$ leaving an orange solution with brownish thick ofl at the bottom. The solution was decanted into a $200-\mathrm{ml}$ round bottom flask. Vacuum distillation gave $95 \mathrm{~g}(52.4 \%)$ of the colorless 2bromopentanoic acid; bp $105-106^{\circ}$ (4 mm) $\left[11 t^{54}\right.$ bp $123-124^{\circ}$ (15 mm)]: nmr $\left(\mathrm{CCl}_{4}\right) 612.8(\mathrm{~s}, 1, \mathrm{COOH}), 4.42(\mathrm{t}, 1, \mathrm{~J}=7.2 \mathrm{~Hz}, \mathrm{CHBrCOOH}), 2.1$ $(\mathrm{m}, \mathrm{r}, \mathrm{CH} \cdot \mathrm{CBr}), 1.8\left(\mathrm{~m}, 2, \mathrm{CH}_{3} \underline{\mathrm{CH}}_{2}\right), 1.0\left(\mathrm{t}, 3, \mathrm{~J}=\% .0 \mathrm{~Hz}, \underline{\mathrm{CH}}_{3}\right)$. 


\section{b. S1lvex 2-bromopentanoateioate 52}

All the operations in this silver galt preparation wore conducted at $0^{\circ}$.

An aqueous solution of ammonia ( $50 \mathrm{ml}$ of concentrated aqueous ammonia in $50 \mathrm{ml}$ of distilled water) was added to the otirred 2bromopentanolc acid (12.2 g, 0.0674 mole) in an Erlenmeyer flaok unt1 the $\mathrm{pH}$ was 7 . Then an aqueous solution of silver nitrate (11.45 8 , 0.0674 mole, in $50 \mathrm{ml}$ of distilled water) was added, and a white prec1pitate formed Immediately. Rapid filtration gave the crude product, which was washed with $150 \mathrm{ml}$ of distilled water, $100 \mathrm{ml}$ of ethyl alcohol, and $150 \mathrm{ml}$ of ethyl ether $\left(\right.$ all at $\left.0^{\circ}\right)$. The precipltate was then transferred to a $100 \mathrm{ml}$ round bottom flask and dried 1n vacuo for 24 hours. In the subsequent reaction, the salt was used directly from the bottle after large lumps were broken up with a spatula.

\section{c. 1 1-Dibromobutane 52}

All apparatus used were dried overnight in the oven. Bromine was dried over phosphorus pentoxide, then distilled. Carbon tetrachloride was dried by distillation and standing over Drfertte. Bromine $(10.8 \mathrm{~g}, 0.0674 \mathrm{~mole})$ and $100 \mathrm{ml}$ carbon tetrachloride were placed in a 250-m1 3-necked round bottom flask equipped with a reflux condenser and a mechanical stirrer. In order to remove any remaining water from the apparatus, the solution was bolled, with no cooling water going through the condenser, unt $112 \mathrm{ml}$ had distilled out the top of the condenser. A calcium chloride drying tube was then fitted into the top of the condenser, the source heat was removed, and the cooling water was turned on. The bottle (kept at $O^{\circ}$ ) containing the silver salt was attached to 
a third neck of the reaction flask by mans of a flextble rubber coupl1ng. The red bromine solution was cooled to $0^{\circ}$. The silver salt was Introduced in sma11 portions with good otirring. Carbon dioxide was IIberated, and the rate was measured by a bubble counter which was connected to the drying tube. A rate of 5-10 bubbles per second was maintalned. At the end of the addition, the reaction mixture was allowed to stir for 30 minutes and to warm to room temperature. The solution was orange after 30 minutes stiring at room temperature. A cold aqueous sodium bloulfite solution was added slowly until the solution became colorless. Sllver bromide was then filtered off and washed with carbon tetrachloride. The combined organic layer was washed with three 20-ml portions of aqueous sodium carbonate solution and three times with water and dxied over Drierite. Carbon tetrachloride was removed by rotary evaporation. Vacuum distillation gave $4.8 \mathrm{~g}(33 \%)$ of the colorless 1,1 -dibromobutane; bp $65-66^{\circ}(20 \mathrm{~mm})\left[11 t^{52}\right.$ bp $90.5-92^{\circ}$ $(101 \mathrm{~mm})] ; \operatorname{nmr}\left(\mathrm{CCl}_{4}\right) \delta 5.70(\mathrm{t}, 1, \mathrm{~J}=6.2 \mathrm{~Hz}, \underline{\operatorname{CHBr}})_{2}, 2.37(\mathrm{~m}, 2$, $\left.\mathrm{CH}_{2} \mathrm{CBr}_{2}\right), 1.60\left(\mathrm{~m}, 2, \mathrm{CH}_{3} \underline{\mathrm{CH}}_{2}\right), 0.98\left(\mathrm{~m}, 3, \mathrm{CH}_{3}\right)$.

\section{Preparation of trang-1,2-dibromocyclopentane}

Cyclopentene $(6.0 \mathrm{~g}, 88$ mmoles $)$ was placed in a $50 \mathrm{ml}$ 3-necked flask covered with aluminum foll and equipped with condenser, magnetic stirrer, thernometer, and additional funnel and cooled to $0^{\circ}$ by an ice bath. A mixture of $14.7 \mathrm{~g}$ (92 moles) of bromine $1 \mathrm{n} 15 \mathrm{ml}$ of carbon tetrachloride was added dropwise from the addition funnel while the temperature was maintained below $2^{\circ}$. At the end of addition, the reaction mixture was allowed to stir further for 10 minutes at $0^{\circ}$ and then allowed to warm to room temperature. The solution was orange. Cold $10 \%$ 
aqueous sodium thlosulfate solution $(1 \mathrm{ml})$ was added to destroy the excess bromine. This reaction mixture was washed with three $5 \mathrm{ml}$ portions of water, drled over calclum chlorlde, and distilled to give $17.1 \mathrm{~g}$ (85\%) of the colorless trans-1,2-dibromocyclopentane; bp $85-87^{\circ}$ (23 mm); $\left[11 t^{55}\right.$ bp $\left.75-76^{\circ}(15 \mathrm{~mm})\right]$.

\section{Preparation of exa-2-bromonorbornane ${ }^{56}$}

2. Preparation of exo-2-bromonorbornane ${ }^{56}$ ied $5.0 \mathrm{~g}(0.053$ mole) of norbornene and $18 \mathrm{~g}$ (excess) of $48 \%$ hydrobromic actd was equipped with condenser and magnetic stirrer. The mixture was stirred and heated at $50-65^{\circ}$ for 2.5 hours. The organtc layer was separated, and the aqueous layer was extracted with three $10-\mathrm{ml}$ portions of ethyl ether. The ethyl ether extracts were combined with the organic layer and washed with $10 \mathrm{ml}$ of water, $10 \mathrm{ml}$ of aqueous sodium bicarbonate, and two $10-\mathrm{ml}$ portions of water. After the organic material had been dried over anhydrous magnesium sulfate, the solvent was removed with rotary evaporation. Distillation gave $6.0 \mathrm{~g}(64 \%)$ of colorless exo-2-bromonorbornane, bp $86-87^{\circ}(31 \mathrm{~mm}) ;\left[11 \mathrm{t}^{56}\right.$ bp $\left.84-87^{\circ}(31 \mathrm{~mm}) ; 80-81^{\circ}(25 \mathrm{~mm})\right]: \mathrm{nmr}\left(\mathrm{CCl}_{4}\right)$ $63.9(\mathrm{~m}, 1, \mathrm{CHBr}), 2.65-0.84(\mathrm{~m}, 10)$.

\section{Preparatton of endo-2-bromonorbornane ${ }^{58}$}

A dry 100-ml, 3-necked, round bottom flask was equipped with a condenser which connected to a nitrogen outlet, a pressure-equalizing dropping funnel which connected to a nitrogen Inlet, a thermometer, and a magnetic stirrer. The system was flushed with nitrogen and then maintained with a positive nitrogen pressure. A mixture of $5.64 \mathrm{~g}(0.060$ mole) of norbornene and $10 \mathrm{ml}$ of dry tetrahydrofuran (THF, dried over calcium hydride and distilled before use) was added to the flask and 
cooled to $0^{\circ}$ with an 1ce-water bath. Borane in THF (21 $\mathrm{ml}$ of a $1 \mathrm{M}$ solution) was added dropwise. The solution was stirred for 30 minutes at $20^{\circ}$, the nitrogen flow was disconnected, and $1 \mathrm{ml}$ of methanol was added to destroy the excess borane. The condenser was replaced by another dropping funnel. One dropping funnel was charged with bromine $(9.6 \mathrm{~g}, 0.060 \mathrm{~mole})$ and the other with a solution of sodium methoxide in methanol ( $17.2 \mathrm{ml}$ of a 3.84 M solution, 0.066 mole of sodium methoxide). The bromine and base were added simultaneously at a rate such that the reaction mixture was always slightly yellow and the reaction temperature was $20-25^{\circ}$. The reaction mixture was allowed to stir further for 20 minutes at room temperature. Water $(10 \mathrm{ml})$ and pentane (25 $\mathrm{m} 1$ ) were added to the reaction mixture, the layers were separated, and the aqueous layer was extracted with three 10-ml portions of pentane. The combined organic solution was washed with $20 \mathrm{ml}$ of water, with $10 \mathrm{ml}$ of saturated aqueous sodium chloride and with two 20-ml portions of water. After being dried with potassium carbonate, the pentane was removed by a rotary evaporator. The crude product was allowed to react with $80 \%$ aqueous ethanol at $55^{\circ}$ for 17 hours to hydrolyze any exo-bromide. 58 The mixture was extracted with three 20 -ml portions of methylene chlorida, and the combined organic material was washed with three $10-\mathrm{ml}$ portions of water. After being dried with anhydrous magnesium sulfate, the methylene chloride was removed on a rotary evaporator. Dist11lation gave $3.2 \mathrm{~g}$ of a fraction, bp $69-71^{\circ}(15.5 \mathrm{~mm})\left[11 t^{59} \mathrm{bp} 69-70^{\circ}(15.5 \mathrm{~mm})\right]$ Gc analysis showed no exo-2-bromonorbornane but did reveal other unident1fied Impurities. Therefore, pure endo-2-bromonorbornane was separated and collected by preparative gc; $\mathrm{nmr}\left(\mathrm{CCl}_{4}\right) \delta 4.21(\mathrm{~m}, 1$, ChBr), $2.60-0.9(\mathrm{~m}, 10)$. 
2. Preparation of 1-bromonorbornane



Formic acid $(88 \%, 31.5 \mathrm{~g}, 0.61$ mole) was added to $14.0 \mathrm{~g}$ (0.149 mole) of norbornene in a 500-ml round-bottom flask equipped with a condenser, and the mixture was bolled under reflux for 4 hours. The dark solution was cooled, and the condenser was arranged for distillation. The excess formic ac1d was removed under reduced pressure; bp $26-31^{\circ}(22 \mathrm{~mm})$. Distillation of the residue gave $16.3 \mathrm{~g}(78 \%)$ of colorless exo-2-norbornyl formate, bp 65-67 (15 mm) [11t $7^{80} 65-67^{\circ}$ $(14-16 \mathrm{~mm})]$; $\mathrm{nmr}\left(\mathrm{CCl}_{4}\right) 87.9(\mathrm{~s}, 1, \underline{\mathrm{HCOO}}), 4.7(\mathrm{~m}, 1$, ChOOㅇ $), 2.5-0.9$ $(\mathrm{m}, 10)$.

\section{b. 2-Norbornanone ${ }^{60}$}

A solution of $15.3 \mathrm{~g}(0.109$ mole) of exo-2-norbornyl formate in $45 \mathrm{ml}$ of reagent grade acetone was contained in a 300-m1 3-necked round bottom flask equipped with a thermometer, stirrer, and dropping funnel. A chromic acid solution, made by dissolving $16.02 \mathrm{~g}$ of chromtum trioxide in ice water, adding $13.32 \mathrm{ml}$ of concentrated sulfuric acid, and diluting the solution to $60 \mathrm{ml}$ with water, was placed in the dropping funnel. The flask was cooled with an ice bath, and the oxidant was added to the stirred solution at a rate to maintain the temperature at $20-30^{\circ}$. The solution was stirred overnlght at room temperature. Solid sodium bisulfite was added in portions to reduce the excess oxtdant. The reaction mixture was decanted into a separatory funnel, washed with three $10-\mathrm{ml}$ portions of saturated aqueous potasstum carbonate solution, and dried over anhydrous potassium carbonate. The acetone was removed by distillation, and $5 \mathrm{ml}$ of benzene was added to remove water 
by azeotropic distillation. When the distillation of solvent was completed and the considerably hotter vapors of product began to ascend the column, the condenser was replaced by an adapter and a collection flask immersed in ice water. The adapter was heated and maintained above $100^{\circ}$ by a free flame until the product began to dist111. Colorless 2norbornanone $(7.6 \mathrm{~g}, 63.2 \%)$ was collected at $170-173^{\circ}\left(11 \mathrm{t}^{59} 170-173^{\circ}\right)$. It cryatallized immediately in the collection flask and melted at $89-91^{\circ}\left(11 t^{60} 90-91^{\circ}\right) ; \operatorname{nmr}\left(\operatorname{Ccl}_{4}\right) \delta 2.67(\mathrm{~m}, 2, \alpha-\underline{H}), 1.75(\mathrm{~m}, 8)$. c. Phosphorus pentabromide ${ }^{81}$

A 100-ml, 3-necked, round bottom flask was equipped with a stirring bar, a condenser, and an addition funnel. A solution $14.4 \mathrm{~g}$ (90 mmoles) of bromlne in $60 \mathrm{ml}$ of petroleum ether was charged to the flask and stirred vigorously. While the flask was chilled by an 1cebath, $24.4 \mathrm{~g}$ (90 moles) of phosphorus trtbromide was added to the solution dropwise. A precipitate formed immediately. When the addition was completed, the reaction mixture was stirred at room temperature for 20 minutes. The solvent was decanted, and the phosihorus pentabromide was washed by decantation with three $20-\mathrm{ml}$ portions of fresh petroleum ether. It was used to prepare 2,2-dibromonorbornane without further purification.

\section{d. 2,2-Dibromonorbornane ${ }^{62}$}

The 100-ml, 3-necked flask which contalned the phosphorus pentabromide was fitted with thermometer, a reflux condenser, and a stirring rod. When 2 -norbornanone $(6.6 \mathrm{~g}, 0.060$ mole) was added to this flask, the mixture liquifled and the temperature rose. The $\mathrm{mix}-$ ture was heated at $70^{\circ}$ for 1 hour and then gradually poured Into water 
at $60-70^{\circ}$ with stirring. After 20 minutes stirring, the mixture was extracted with two $25 \mathrm{ml}$ portions of dichloromethane. The extracts were combined, washed with $10 \mathrm{ml}$ of $2 \mathrm{M}$ aqueous sodium hydroxide and with two $10 \mathrm{ml}$ portions of water, and dried over magnesium sulfate. Solvent was removed by rotary evaporation. Distillation gave $11.0 \mathrm{~g}$ of colorless 2,2-dibromonorbornane, bp $76-80^{\circ}$ (1.5 mm). The ir spectrum Included absorption at $1750 \mathrm{~cm}^{-2}$ which indicated the unreacted starting ketone. Redistillation falled to remove this starting ketone. The product mixture was then washed with cold concentrated sulfuric acid until no yellow color showed in the sulfurtc actd layer. The organtc layer was then washed with $10 \mathrm{ml}$ of water with $10 \mathrm{ml}$ of $10 \%$ sodium carbonate, and with two $10^{-m 1}$ portions of water and then drled over magneslum sulfate. Distillation gave $7.6 \mathrm{~g}(50.7 \%)$ of product without carbonyl group in absorption; bp $71-73^{\circ}$ (2.2 mm); nmr $\left(\mathrm{Ccl}_{4}\right) \delta 3.5-0.9$ (m, all peaks). Anal. Calcd, for $\mathrm{C}_{7} \mathrm{H}_{10} \mathrm{Br}_{2}: \mathrm{C}, 33.07 ; \mathrm{H}, 3.97$. Found: C, 33.18; H, 3.91.

\section{e. 1-Bromonorbornane}

The procedure paralleled one published for the preparation of 1-chloronorbornane from $2,2-\mathrm{d} 1 \mathrm{ch}$ loronorbornane. 63

A solution was prepared by mixing $6.0 \mathrm{~g}$ (23.6 mmoles) of 2,2dibromonorbornane, $5 \mathrm{ml}$ of isopentaue, and $17 \mathrm{ml}$ of pentane. (Both pentanes were purifled by being stirred with anhydrous aluminum bromide and then distilled before use.) While the solution was stirred in a 100-ml, 3-necked, round bottom flask equipped with a reflux condenser, powdered anhydrous aluminum bromide $(2.76 \mathrm{~g}, 10.3$ mmoles $)$ was added in small portions as rapidly as the hydrogen bromide evolution would permit. 
The stirring was continued for 6 hours at room temporature. The pentane layer was decanted, and the dark sludge which remainod in the flask wao washed with four 5-m1 portions of purifled pentane. The combined pentane solution was washed with $5 \mathrm{ml}$ of water, $5 \mathrm{ml}$ of aqueous sodium b1carbonate solution, and two 5-ml portions of vater. After the solution had drfed over anhydrous sodfum sulfate, the pentanes were removed by rotary evaporation. Distillation gave four fractions: (1) $0.48 \mathrm{~g}(7 \%)$, bp $50-58^{\circ}(15 \mathrm{~mm}) ; \quad$ (2) $0.5 \mathrm{~g}(13.5 \%)$, bp $58-68^{\circ}(15 \mathrm{~mm})$; (3) $0.5 \mathrm{~g}$ (13.5\%), bp 68-88 (15 m); and (4) $2.1 \mathrm{~g}(42 \%)$, bp $84-87^{\circ}$ (1.5 mm). The first three fractions were identifled by $n m$ r to be mixtures of 1 bromonorbornane, exo- and endo-2-bromonorbornanes, and the fourth fraction was identified by $\mathrm{nmr}$ to be dibromonorbornanes. [L1t ${ }^{\mathrm{BA}}$ ibromonorbornane, bp $56^{\circ}(18 \mathrm{~mm}), 57-58^{\circ}$ (21 mm).] 1-Bromonorbornane was separated from the monobromonorbornane fractions by preparative gc. All peaks in the nmr spectrum of 1-bromonorbornane were between $\delta 2.4$ and 61.0 .

c. Brominations

L. Materials

Commercial bromine (reagent grade) was distilled in flamedried apparatus through a short column at $59^{\circ}$ and collected. The inttial cut of about $3 \mathrm{ml}$ and final cut of about $3 \mathrm{ml}$ were discarded. The distillation was stored over phosphorus pentoxide and redistilled just before use.

N-Bromosuccinimide (NBS) was recrystallized from hot water and dried in a desiccator (calclum chloride desiccant) protected from light. It was deterulned to be $99.8 \pm 0.1 \%$ pure by $t i t$ ration with aqueous thlosulfate solution. 
Commerclally avallable compounds to be brominatad and solvents were purifled by standard methodo as deacribed In "Organic Solvents" by Rlddick and Bunger. ${ }^{155}$

\section{General procedure for bromination}

The dried small glass ampoules (inside diameter $8.5 \mathrm{~mm}$, outside diameter $10 \mathrm{~mm}$ ) were covered with aluminum foll; charged with a mixture of compound(s) to be brominated, brominating reagent, and solvent, if one were used; Incorporated into a vacuum line apparatus and degassed by a freeze-thaw method; sealed off; placed in a water bath at the selected reaction temperature; and Irradiated with a $300 \mathrm{w}$ Incandescent lamp $30 \mathrm{~cm}$ from the ampoules. After different times, one by one of the ampoules was removed, Immediately frozen in liquid nitrogen, and opened. Except for the experiments in which a large excess of bromine was used, the reaction mixture $(1.0 \mathrm{ml})$ was added to a mixture of about $10 \mathrm{ml}$ of $10 \%$ potassium 1odide, $1 \mathrm{ml}$ of Freon 113 , and about $2 \mathrm{ml}$ of 1 M hydrochloric ac1d. A brown solution showed lodine formation. Th1s brown solution was titrated with standard aqueous sodium thiosulfate until the solution became light yellow. Starch indicator ( $1 \mathrm{ml}$ ) was added, and the solution became blue. Titration was continued until the blue color disappeared. The quantity (rmol) of thlosulfate consumed was equivalent to the quantity (mmol) of bromine or NBS remaining. The organic layer was pipetted into a small sample vial and was analyzed by gc for product distribution. Authentic samples of products were used for gc identifications and standardizations. 


\section{a. Bromination of butyl bromide by bromine}

Run 1: Four ampoules were each charged with about $2 \mathrm{ml}$ of a mixture of butyl bromlde and bromine (mol rat1o, 5.9:1.0; no solvent) and Irradfated at $4 \pm 1^{\circ}$. After work-up, the gc analyois showad the product distribution as below."

\begin{tabular}{ccccc}
$\begin{array}{c}\text { Time } \\
\text { min. }\end{array}$ & $\begin{array}{c}\text { \% Con- } \\
\text { version }\end{array}$ & \multicolumn{3}{c}{$\%$ of 1Bomeric dibrumobutanes } \\
1,1 & 1,2 & 1,3 \\
4 & 1.01 & 0.8 & 90.9 & 8.3 \\
& & $(0.1)$ & $(11)$ & $(1.0)$ \\
10 & 2.12 & $\begin{array}{c}0.8 \\
(0.1)\end{array}$ & $\begin{array}{c}90.9 \\
(11)\end{array}$ & $\begin{array}{c}8.3 \\
(1.0)\end{array}$ \\
25 & 3.42 & 0.8 & 90.9 & 8.3 \\
& & $(0.1)$ & $(11)$ & $(1.0)$ \\
63 & 13.05 & 0.8 & 90.9 & 8.3 \\
& & $(0.1)$ & $(11)$ & $(1.0)$
\end{tabular}

Run 2:: Seven ampoules were each charged with about $2 \mathrm{ml}$ of a mixture of butyl bromide and bromine (mole ratto, 6.8:1.0; no solvent) and Irradiated at $25 \pm 1^{\circ}$. After work-up, the gc analys ds showed the product distribution as below.

\footnotetext{
* In each report of product distributions that follow, figures not in parentheses record the relative yleld of dibromobutanes in the total product mixture, while those in parentheses show the amounts of dibromobutanes only relative to the 1,3 -isomer.
} 


\begin{tabular}{|c|c|c|c|c|}
\hline $\begin{array}{l}\text { Time } \\
\text { min. }\end{array}$ & $\begin{array}{l}\% \text { Con- } \\
\text { version }\end{array}$ & \multicolumn{3}{|c|}{$\%$ of isomeric dibromobutanes } \\
\hline 2 & 1.37 & * & $\begin{array}{l}88.0 \\
(7.3)\end{array}$ & $\begin{array}{l}12.0 \\
(1.0)\end{array}$ \\
\hline 4 & '2.9' & * & $\begin{array}{l}88.0 \\
(7.5)\end{array}$ & $\begin{array}{l}12.0 \\
(1.0)\end{array}$ \\
\hline 8 & 6.41 & $\begin{array}{r}1.15 \\
(0.1)\end{array}$ & $\begin{array}{l}87.4 \\
(7.6)\end{array}$ & $\begin{array}{l}11.5 \\
(1.0)\end{array}$ \\
\hline 16 & 10.5 & $\begin{array}{l}1.16 \\
(0.1)\end{array}$ & $\begin{array}{l}87.2 \\
(7.5)\end{array}$ & $\begin{array}{l}11.6 \\
(1.0)\end{array}$ \\
\hline 32 & 22.1 & $\begin{array}{c}1.2 \\
(0.1)\end{array}$ & $\begin{array}{l}86.9 \\
(7.3)\end{array}$ & $\begin{array}{l}11.9 \\
(1.0)\end{array}$ \\
\hline 64 & 43.5 & $\begin{array}{c}1.2 \\
(0.1)\end{array}$ & $\begin{array}{l}86.9 \\
(7.3)\end{array}$ & $\begin{array}{l}11.9 \\
(1.0)\end{array}$ \\
\hline 128 & 75.4 & $\begin{array}{c}1.0 \\
(0.1)\end{array}$ & $\begin{array}{l}89.0 \\
(8.9)\end{array}$ & $\begin{array}{l}10.0 \\
(1.0)\end{array}$ \\
\hline
\end{tabular}

Run 2: Five ampoules were each charged with about $2 \mathrm{ml}$. of a mixture of butyl bromtde and bromine (mole ratio, 7.5:1.0; no solvent) and irradiated at $60.7 \pm 1.5^{\circ}$. After work-up, the gc analysis showed the product distribution as below.

\begin{tabular}{ccccc}
$\begin{array}{c}\text { Time } \\
\text { min. }\end{array}$ & $\begin{array}{c}\text { \% Con- } \\
\text { version }\end{array}$ & \multicolumn{3}{c}{$\%$ of 1someric dibromobutanes } \\
1,1 & 1,2 & 1,3 \\
1 & 1.74 & $\begin{array}{c}1.8 \\
(0.1)\end{array}$ & $\begin{array}{l}80.3 \\
(4.5)\end{array}$ & $\begin{array}{c}17.9 \\
(1.9)\end{array}$ \\
3 & 22.5 & 1.6 & 80.5 & 17.9 \\
& & $(0.09)$ & $(4.5)$ & $(1.0)$ \\
10 & 71.5 & 1.6 & 82.5 & 15.9 \\
& & $(0.10)$ & $(5.2)$ & $(1.0)$ \\
25 & 89.8 & 1.6 & 83.7 & 14.7 \\
& & $(0.11)$ & $(5.7)$ & $(1.0)$ \\
40 & 99.8 & 1.4 & 84.7 & 13.9 \\
& & $(0.11)$ & $(6.1)$ & $(1.0)$
\end{tabular}

$\left[\operatorname{Lit}^{4} 0.9 \%: 84.3 \%: 14.6 \%=1,1: 1,2: 1,3\right.$ for $100 \%$ conversion at $\left.(0)^{\prime \prime}.\right]$ 
Run 4: Two ampoules were each charged with a mixture of butyl bromide and bromine (mole ratio, 1:100; no solvent) and were trradiated at $60 \pm 1^{\circ}$. When each tube was opened, Freon $113(1 \mathrm{ml})$ was added to the mixture. A yellow precipitate (sulfur) formed when the excegs bromine was destroyed by 1ce-cold aqueous sodfum thiosulfate. This reaction mixture was centrifuged, and the organic layer (Freon 11) layer) was pipetted into a vial. The gc analysis showed the product distribution $( \pm 0.2 \%$ max $)$ as below.

\begin{tabular}{|c|c|c|c|c|}
\hline Time & Reaction & \multicolumn{3}{|c|}{ \% of 1somertc dibromobutanes } \\
\hline $\mathrm{min}$. & & 1,1 & 1,2 & 1,3 \\
\hline 10 & 1 & $\begin{array}{c}1.6 \\
(0.1)\end{array}$ & $\begin{array}{l}82.5 \\
(5.2)\end{array}$ & $\begin{array}{l}15.9 \\
(1.0)\end{array}$ \\
\hline 20 & 3 & $\begin{array}{c}1.6 \\
(0.1)\end{array}$ & $\begin{array}{l}82.8 \\
(5.3)\end{array}$ & $\begin{array}{l}15.6 \\
(1.0)\end{array}$ \\
\hline
\end{tabular}

b. Bromination of butyl bromide by NBS

b. Bromination of buty 1 bromide by NBS

Run 5: Six ampoules were each charged with about $2 \mathrm{ml}$ of a mixture of butyl bromide, NBS, and acetonitrile (mole rat1o, 1.0:5.9:27) and Irradiated at $60 \pm 1^{\circ}$. After work-up, the gc analysis showed the product distribution as below.

\begin{tabular}{|c|c|c|c|c|c|}
\hline Time & of NBS & of of 1 & meric & Albromo & :anes \\
\hline $\mathrm{m} 1 \mathrm{n}$ & consumed & 1,1 & 1,2 & 1,3 & 1,4 \\
\hline 4 & 5.4 & $\begin{array}{l}16.5 \\
(0.29)\end{array}$ & $\begin{array}{l}17.0 \\
(0.30)\end{array}$ & $\begin{array}{l}56.8 \\
(1.0)\end{array}$ & $\begin{array}{l}9.7 \\
(0.17)\end{array}$ \\
\hline 30 & 35.7 & $\begin{array}{l}14.1 \\
(0.27\end{array}$ & $\begin{array}{l}27.6 \\
(0.53)\end{array}$ & $\begin{array}{l}52.0 \\
(1.0)\end{array}$ & $\begin{array}{c}6.3 \\
(0.12)\end{array}$ \\
\hline 62 & 58.1 & $\begin{array}{l}10.9 \\
(0.24)\end{array}$ & $\begin{array}{l}40.3 \\
(0.89)\end{array}$ & $\begin{array}{l}45.2 \\
(1.0)\end{array}$ & $\begin{array}{l}3.6 \\
(0.08)\end{array}$ \\
\hline 105 & 80.5 & $\begin{array}{c}8.3 \\
(0.20)\end{array}$ & $\begin{array}{l}47.9 \\
(1.16)\end{array}$ & $\begin{array}{l}41.3 \\
(1.0)\end{array}$ & $\begin{array}{c}2.5 \\
(0.06)\end{array}$ \\
\hline 165 & 93.5 & $\begin{array}{c}8.5 \\
(0.20)\end{array}$ & $\begin{array}{l}46.6 \\
(1.10)\end{array}$ & $\begin{array}{l}42.4 \\
(1.0)\end{array}$ & $\begin{array}{l}2.5 \\
(0.06)\end{array}$ \\
\hline 230 & 95.5 & $\begin{array}{c}9.5 \\
(0.23)\end{array}$ & $\begin{array}{l}46.7 \\
(1.13)\end{array}$ & $\begin{array}{l}41.3 \\
(1.0)\end{array}$ & $\begin{array}{c}2.5 \\
(0.00)\end{array}$ \\
\hline
\end{tabular}


c. Competitive bromination of butyl bromide and cyclohexane by bromine

Run 6: Three ampoules were each charged with about $2 \mathrm{ml}$ of a mixture of butyl bromide, cyclohexane, and bromine (mole ratio, 10:10:1; no solvent) and irradlated at $60 \pm 1^{\circ}$. After work-up, the gc analysis showed the product distribution $( \pm 0.2 \% \max )$ as below. The relative reactivity was butyl bromide: cyclohexane $=2.3: 1$.

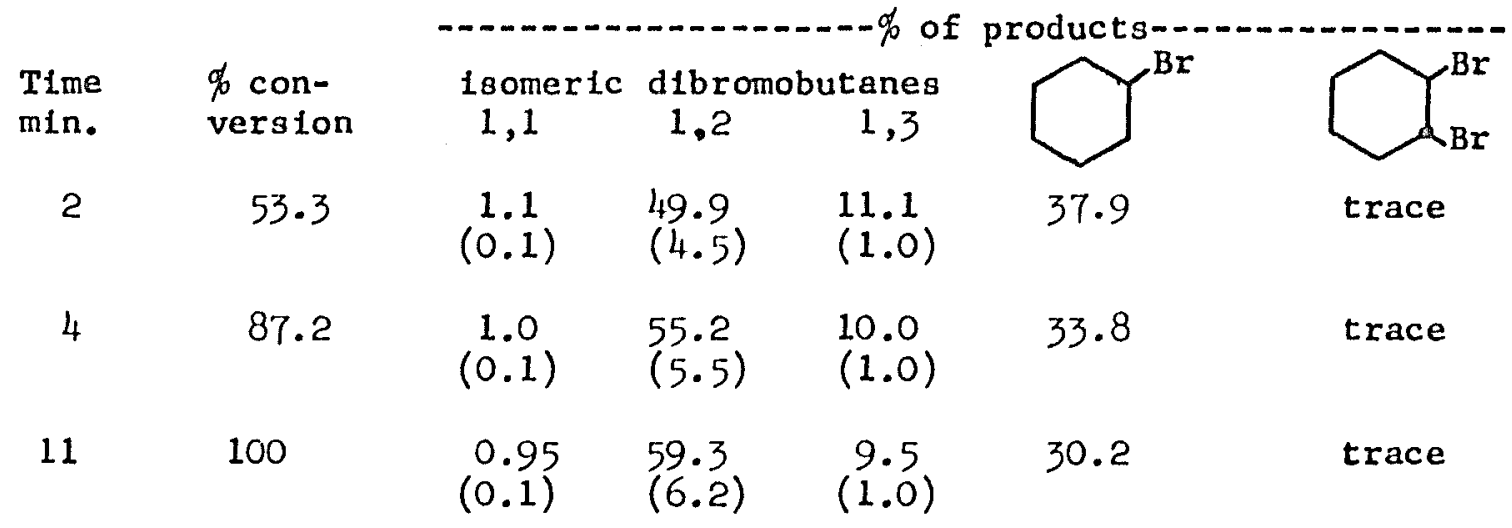

Run I: Two ampoules were each charged first with a mixture of butyl bromide and cyclohexane (mole ratio, 1:1; no solvent) and then with 100 mole equiv of bromine and were irradlated at $60 \pm 1^{\circ}$. Freon 113 ( $1 \mathrm{ml}$ ) was added to each opened ampoule. A yellow precipttate (sulfur) formed when the excess bromine was destroyed by ice-cold aqueous sodium thlosulfate. This reaction misture was centrifuged, and the organic layer (Freon 113 layer) was pipetted into a vlal. The gc analysis showed the product distribution $( \pm 0.1 \%$ maxs) as below. The relative reactivity was butyl bromide:cyclohexane $1: 3.1$. 


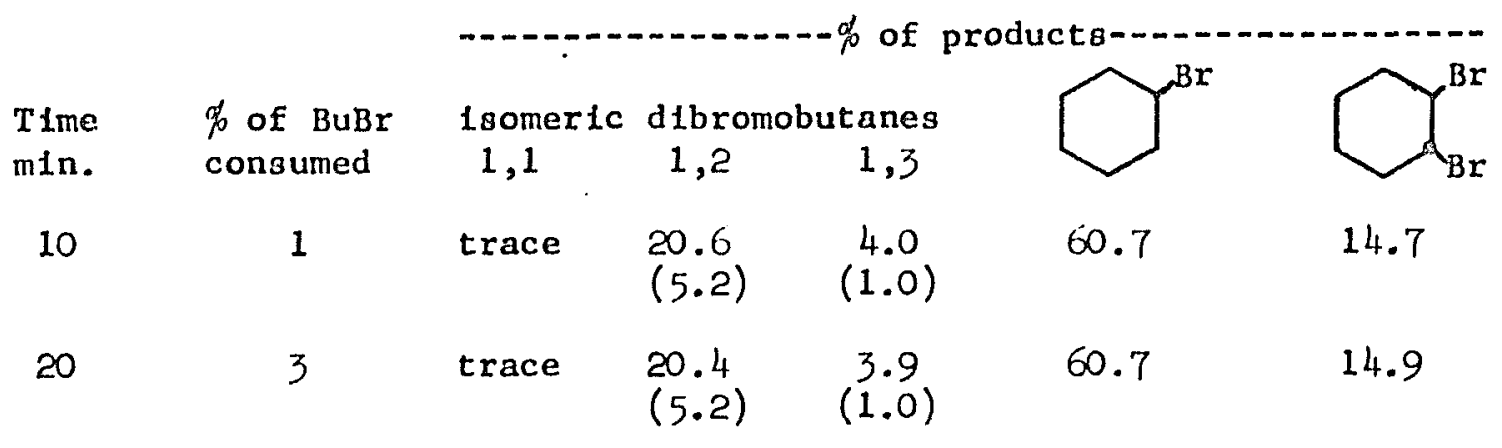

d. Compet1tive bromination of butyl bromide and cyclohexane by NBS

Run 8: Two ampoules were each charged with about $2 \mathrm{ml}$ of a mixture of butyl bromide, cyclohexane, and acetonitrile (mol ratio, 10:10:26.5) saturated with NBS (1ess than 1 mol equiv), and irradiated at $60 \pm 1^{\circ}$. After work-up, the gc analysis showed the product distribution $( \pm 0.3 \% \max )$ as below. The relative reactivity was butyl bromide: cyclohexane $=0.20: 1$.

\begin{tabular}{|c|c|c|c|c|c|c|}
\hline \multirow{2}{*}{$\begin{array}{l}\text { Time } \\
\text { min. }\end{array}$} & \multirow{2}{*}{$\begin{array}{l}\% \text { Con- } \\
\text { version }\end{array}$} & \multicolumn{5}{|c|}{ q of products } \\
\hline & & 1,1 & 1,2 & 1,3 & 1,4 & hexane \\
\hline 2 & 26.9 & $\begin{array}{c}1.6 \\
(0.28)\end{array}$ & $\begin{array}{c}2.8 \\
(0.50)\end{array}$ & $\begin{array}{l}5.7 \\
(1.0)\end{array}$ & trace & 89.9 \\
\hline 75 & 97.7 & $\begin{array}{c}1.5 \\
(0.23)\end{array}$ & $\begin{array}{l}8.3 \\
(1.25)\end{array}$ & $\begin{array}{c}6.6 \\
(1.0)\end{array}$ & $\begin{array}{c}0.5 \\
(0.07)\end{array}$ & 83.1 \\
\hline
\end{tabular}

e. Compettive bromination of cyclopentane and cyclohexane by bromine

Run 2: Three ampoules were each charged with about 2 m1 of a mixture of cyclopentane, cyclohexane, and bromine (mole ratio, 10:10:1;

* It was intended to use a 10:10:1:26.5 moie ratio of butyl bromide:cyclohexane:NBS: acetonttrile; however, the NBS was only partially soluble in the mixture, so this saturated NBS solution at $25^{\prime}$ was used. 
no solvent) and irradiated at $60 \pm 1^{\circ}$ unt 11 the reaction mixture turned colorless (ㅁ․․․, 100\% converston). After work-up, the gc analysts revealed the average product distribution: bromocyclopentane $(72.4 \pm$ $0.4 \%)$, trans $-1,2-d$ ibromocyclopentane $(14.8 \pm 0.5 \%)$, bromocyclohexane $(12.8 \pm 0.1 \%)$, and trace amount of trans-1,2-dibromocyclohexane. The relative reactivity was cyclopentane: cyclohexane $=6.8: 1$.

Run 10: Two ampoules were each charged first with a mixture of cyclopentane and cyclohexane (mole ratio, 1:1; no solvent) and then with 100 mole equiv of bromine and irradiated at $60 \pm 1^{\circ}$ for 70 seconds. Freon $113(1 \mathrm{~m} 1)$ was added to each opened ampoule. When excess bromine was destroyed by 1 ck-cold aqueous sodium thiosulfate, a yellow prectpitate (sulfur) formed. This reaction mixture was centrifuged, and the organic layer (Freon 113 layer) was plpetted into a via. The gc analysis revealed that $2.1 \%$ of the cyclohexane had been consumed, and the average product distribution: bromocyclopentane $(71.8 \pm 0.3 \%)$, trans $-1,2-d 1 b r o m o-$ cyclopentane $(17.1 \pm 0.3 \%)$, bromocyclohexane $(10.0 \pm 0.2 \%)$, and trans$1,2-\mathrm{d} 1 \mathrm{~b}$ romocyclohexane $(1.1 \pm 0.3 \%)$. The relative reactivity was cyclopentane: cyclohexane $=8.0: 1$.

\section{f. Compet1tive bromination of cyclopentane and cyclohexane by}

督

Run 11: Two ampoules were each charged with about $2 \mathrm{ml}$ of a methylene chloride solution of cyclopentane, cyclohexane and NBS (mole ratio, cyclopentane: cyclohexane:NBS: methylene chlortde = 10:10:1:132) and Irradiated at $60 \pm 1^{\circ}$ for one hour. Titration with aqueous sodium thlosulfate showed reaction to be $99 \%$ complete. The gc analysis revealed the average product distribution: bromocyclopentane $(62.3 \pm 0.2 \%)$ and bromocycloherane $(37.7 \pm 0.2 \%)$. The relative reactivity wa cyclopentane:cyclohexane $1.6: 1$. 


\section{B. Brominat 1on of cyclopropane by bromine}

Run 12: Two ampoules chilled in liquid nitrogen were each charged first with $0.76 \mathrm{~g}$ (18 moles) of cyclopropane and then with a solution of $0.1 \mathrm{ml}$ ( 1.8 mmoles) of bromine $1 \mathrm{n} 1 \mathrm{ml}$ of methylene chloride (mole ratio, cyclopropane:bromine:methylene chloride $=10: 1: 8.6$ ) and irradiated at $0 \pm 1^{0}$ for 6 hours. The reaction mixture changed color from brown to colorless (1..e., 100\% converston). After work-up, the gc analysis of both ampoules showed only 1,3-dibromopropane formed in the reaction mixture. ${ }^{48} 1,3$-Dibromopropane was identified by comparing the gc retention time with that of a commercial sample.

Run 13: Two ampoules were each charged with $0.027 \mathrm{~g}(0.65$ mole) of cyclopropane and bromine $(4 \mathrm{ml}, 65$ mmoles) and 1rradiated with the lamp at $0 \pm 1^{\circ}$, one for $30 \mathrm{minutes}$ and the other for $90 \mathrm{~m} 1 \mathrm{n}$ utes. Freon $113(1 \mathrm{ml})$ was added to each opened ampoule. A yellow precipitate (sulfur) formed when the excess bromine was destroyed by ice-cold aqueous sodium thiosulfate. This reaction mixture was centrifuged, and the organic layer (Freon 113 layer) was plpetted into a vial. The gc analysis revealed only 1,3-dibromopropane formed. No cyclopropyl bromide was detected.

\section{h. Bromination of cyclopropane by NBS}

Run 14: Two ampoules were each charged with first $1.68 \mathrm{~g}(40$ moles) of cyclopropane and then with a solution of $0.71 \mathrm{~g}$ ( 4 mmoles) of NBS in $2 \mathrm{ml}$ of acetonitrile (mole ratio, cyclopropane:NBS:acetonitrile = $10: 1: 9.4)$. Some NBS precipitated, but the solid NBS disappeared during the 10 hours of Irradiation at $0 \pm 1^{\circ}$. Thiosulfate titration showed that all NBS had been consumed. The gc analysis of both ampoules revealed the following product distribution: 1,3 -dibromopropane $(<2 \%)$, 
and bromocyclopropane $(>98 \%)$. 1,3-Dibromopropane and bromocyclopropane were identified by comparing the gc retention times with those of commercial samples.

\section{11. Bromination of norbornane by bromine}

Run 15: T'wo ampoules were each charged with a Freon 113 solution of norbornane and bromine (mole ratio, norbornane:bromine: Freon $113=6.95: 1: 16)$, and trradiated at $60 \pm 1^{\circ}$ for 4.5 hours. The reaction mixture changed color from brown to colorless (1‥e., 100\% conversion). The gc analysis revealed the average product distribution: exo-2-bromonorbornane $(67.7 \pm 0.8 \%)$, endo-2-bromonorbornane $(32.3 \pm$ $1.0 \%)$, and sma11 amount of dibromonorbornanes.

\section{i. Bromination of norbornane by NBS}

Run 16: Three ampoules were each charged with a methylene chloride solution of norbornane and NBS (mole ratio, norbornane:NBS: methylene chloride $=6.78: 1: 117$ ) and 1 rradiated at $60 \pm 1^{\circ}$ for 4.5 hours. Thiosulfate titration showed that all NBS had been consumed. The gc analysis revealed the average product distribution: exo-2bromonorbornane $(72.3 \pm 0.5 \%)$, endo-2-bromonorbornane $(19.7 \pm 0.8 \%)$, and 1 -bromonorbornane $(8.0 \pm 0.1 \%)$.

\section{k. Preparation of exo- and endo-2-bromonorbornanes by Kocht} reaction 18

exo-2-Norbornanecarboxylic actd $(2.8 \mathrm{~g}, 0.02$ mole, prepared by S. D. Elakovich), $20 \mathrm{ml}$ of benzene, $8.86 \mathrm{~g}(0.02$ mole) of lead tetraacetate, and $2.06 \mathrm{~g}(0.02$ mole $)$ of sodium bromide were placed consecutively in a 50-ml 3-neck round bottom flask fitted with a reflux condenser, a magnetic stirrer, and a nitrogen inlet. The condenser was 
protected with a calclum chloride drylng tube. The dark red misture was heated at reflux for four hours. The resultant yellow liquid was separated from the brown precipitate. The filtrate was washed with dilute aqueous perchloric acid-sodium chloride solution, twice with 25-ml portions of sodium carbonate, and thrice with 25-ml portions of distilled water. It was dried over anhydrous magnesium sulfate overnight. The solution was filtered, and the gc analysis revealed the product distribution: exo-2-bromonorbornane $(64.3 \%)$ and endo-2-bromonorbornane $(35.7 \%)$.

\section{\&. Bromination of ethylbenzene by NBS}

Run 17: An ampoule was charged with $2 \mathrm{ml}$ of a solution of NBS In acetonitrile and then with ethylbenzene (mole ratio, NBS: ethylbenzene: acetonitrile $=1: 10: 19)$ and 1 rradiated at $60 \pm 1^{\circ}$ for one hour. The sodium thiosulfate titration indicated 100\% conversion. After work-up, the gc analysis showed styrene (formed by dehydrobromination in the gc instrument), $\alpha$-bromoethylbenzene, and a trace amount of $\beta$-bromoethylbenzene. The attempt to detect th $1 \mathrm{~s}$ ?-bromoethylbenzene falled because of the limitation of the sensitivity of the nmr instrument. D. Miscellaneous Control Experiments

\section{Control reaction for bromination of butyl bromide by bromine} and by NBS

Analysis of mixtures of butyl bromide and bromine or NBS which were prepared as for Run 1 to Run 5 but not frradlated showed no bromination product. 


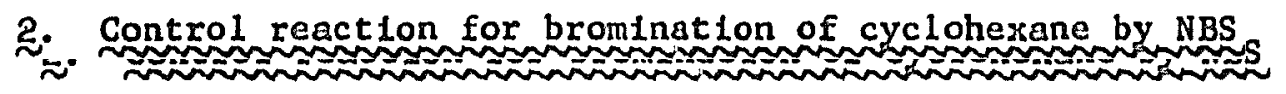

An ampoule was charged with a mixture of cycloherane, NBS, and acetonterile [saturated aolution obtained by mizing cyclohorane, NBS, and acetonttrile (mole ratio, 10:1:26.5)] and heated at $60 \pm 1^{\circ}$ for 5 hours but not 1rradlated. Work-up as described in the General Procedure and gc analysts showed no bromination product.

\section{Control reaction for bromination of cyclopropane by bromine}

Analysis of a mixture of cyclopropane and bromine which was prepared as for Run 12 but not irradlated showed no 1,3-d1bromopropane.

\section{Addition of bromine to norbornene}

Norbornene $(10 \mathrm{~g}, 0.105$ mole) in $20 \mathrm{ml}$ of carbon tetrachloride was placed in a 100-ml 3-neck round bottom flask equipped with a reflux condenser, an addition funnel, and a magnetic stirrer. The mixture was stirred and cooled to $-10^{\circ}$ with an 1ce-salt bath. A solution of $14.5 \mathrm{~g}$ (0.09 mole) of bromine in $10 \mathrm{ml}$ of carbon tetrachlortde was added dropwise with stirring at a rate such that the temperature remained at or just below $0^{\circ}$. After the bromine solution had been added, the persistence of red color and lack of exothermictity indicated that the olefin had been consumed. Bromine was quenched by the addition of $25 \mathrm{ml}$ of an aqueous sodium thiosulfate solution (prepared by adding water to $20 \mathrm{~g}$ of pure sodium thiosulfate to make $100 \mathrm{ml}$ of solution. The reaction mixture was filtered to remove sulfur, washed with two 20-ml portions of distilled water, and dried over anhydrous magnesium sulfate overnight. A mixture was obtained; the gc pattern agreed with that reported. 49 


\section{Brominat1on of exo- and endo-2-bromonorbornanes by brom1ne}

Four ampoules were each charged with about $2 \mathrm{~m} 1$ of a mixture of $2.8 \mathrm{~g}$ (16 monoles) of exo- and endo-2-bromonorbornanes (exo/endo = $1.8), 0.17 \mathrm{~g}$ of bromine ( 1.06 moles), and $14.9 \mathrm{~g}$ of Freon 113, and Irradiated at $60 \pm 1^{0}$ for different times. Thiosulfate titrations showed the conversions to be $54 \%(6 \mathrm{~min}), 79 \%(13 \mathrm{mIn}), 98 \%(25 \mathrm{~min})$ and $100 \%(40 \mathrm{mln}$ ). After work-up, all of the gc patterns of dibromonorbornanes were the same as that obtained from bromfnation of norbornane and different from that obtalned from the addition of bromine to norbornene. The unreacted bromonorbornanes in these four runs all remained exo/endo $=1.8$.

\section{Control reaction of bromination of exo- and endo-2obromonorbor-} nanes by bromine

An ampoule was charged with a mixture of exo- and endo-2bromonorbornanes, bromine, and Freon 113, as in control experiment 5, and heated at $60 \pm 1^{\circ}$ without irradiation for 4 hours. The gc analysis showed no bromination product, and the reactant exo/endo ratio remalned 1.8 . 


\section{REFERENCES}

1. (a) P. S. Fredericks and J. M. Tedder, J. Chem. Soc., 144 (1960);

(b) P. S. Fredericks and J. M. Tedder, J. Chem. Soc., 3520 (1961).

2. M. S. Kharasch, W. S. Z1mmt, and W. Nudenberg, I. Org. Chem., 20, $1430(1931)$.

3. (a) H. Singh and J. M. Tedder, J. Chem. Soc., 4737 (1964);.

H. Singh and J. M. Tedder, J. Chem. Soc. (B), 608 (1966).

4. W. A. Thaler, J. Amer. Chem. Soc., 85, 2607 (1963).

5. A. Streltwelser, "Solvolytic Displacement Reactions" Chapter 5 , McGraw-H111, New York, N. Y., 1962.

6. H. L. Goering, P. I. Abe11, and B. F. Aycock, J. Amer. Chem. Soc., 74,3588 (1952).

7. J. G. Traynham and W. G. Hines, J. Amer. Chem. Soc., 20, 5208 (1968).

8. K. B. W1berg and L. H. Slaugh, J. Amer. Chem. Soc., 80, 3033 (1958).

9. H. R. Anderson, H. A. Scheraga, and E. R. Van Artsdalen, I. Chem. Phys., 21, 1258 (1953).

10. C. Walling, A. L. Rieger, and D. D. Tanner, J. Amer. Chem. Soc., $85,3129(1963)$.

11. R. E. Pearson and J. C. Martin, J. Amer. Chem. Soc., 85, 3142 (1963).

12. K. J. Shea, D. C. Lew1s, and P. S. Skell, J. Amer. Chem. Soc., 25, $7768(1973)$

13. P. S. Ske1l and K. J. Shea, J. Amer. Chem. Soc., 24, 6550 (1972).

14. E. S. Lew1s and S. Kozuka, J. Amer. Chem. Soc., 22, 282 (1973).

15. L. Melander, "Isotope Effects on Reaction Rates", Ronald Press, New York, N. Y., 1962, pp. 9-15.

16. J. A. Kerr, Chem. Rev., 66, 465 (1966). 
17. P. S. Ske11 and P. D. Read10, J. Amer. Chem. Soc., 86, 3334 (1964).

18. E. S. Huyser and R. H. C. Feng, J. Org. Chem., 26,131 (1971).

19. P. S. Ske11, D. L. Tuleen, and P. D. Read1o, J. Amer. Chem. Soc., 85, $2849(1963)$

20. K. J. Shea and P. S. Ske11, J. Amer. Chein. Soc., 25, 283 (1973).

21. P. S. Skell, R. R. Pavlis, D. C. Lewls, and K. J. Shea, J. Amer. Chem. Soc., 25, 6735 (1973).

22. P. S. Skell and K. J. Shea, "Free Radicals", Vol. II, WileyInterscience, New York, N. Y., 1973, Chapter 26.

23. A. R. Lyons and M. C. R. Symons, I. Amer. Chem. Soc., 23, 7330 (1971).

24. (a) D. D. Tanner, D. Darwish, M. W. Mosher, and N. J. Bunce, I. Amer. Chem. Soc., 21, 7398 (1969); (b) D. D. Tanner, M. W. Mosher, N. C. Das, and E. V. Blackburn, J. Amer. Chem. Soc., 2Z, 5846 (1971); (c) D. D. Tanner, H. Yabuuch1, and E. V. Blackburn, J. Amer. Chem. Soc., 23, 4802 (1971); (d) D. D. Tanner, J. E. Rowe, T. Pace, and Y. Kosug1, I. Amer. Chem. Soc., 25, 4705 (1973).

25. K. Zlegler, A. Spaeth, E. Schaaf, W. Schumaan, and E. Winkelmann, Ann. , 251, 80 (1942).

26. D. H. Hey, Ann. Rpts. Chem. Soc., 4 1, 184 (1944).

27. G. F. Bloomfleld, J. Chem. Soc., 114 (1944).

28. J. Adam, P. A. Gossela1n, and P. Goldfinger, Nature, $\mathbf{1} 7 \mathbf{1}, 704$ (1953).

29. F. L. J. Sixma and R. H. Reim, Konlnk1. Ned. Akad. Wetengchap. Proc., 61B, 183 (1958).

30. B. P. McGrath and J. M. Tedder, Proc. Chem. Soc., 80 (1961).

31. E. C. Kooyman, R. Van Helden, and A. F. Bickel, Konink1. Ned. Akad. Wetenschap. Proc., $56 \mathrm{~B}, 75$ (1953). 
32. R. E. Pearson and J. C. Martin, J. Amer. Chem. Soc., 85, 354 (1963).

33. (a) G. A. Russell, C. D. Deboer, and K. M. Desmond, J. Amer. Chem. Soc., 85, 365 (1963); (b) G. A. Russell and K. M. Desmond, I. Amer. Chem. Soc., 85, 3139 (1963).

34. M. L. Poutsma, "Free Radicals", Vo1. II, J. K. Koch1, Ed., WileyInterscience, New York, N. Y., 1973, p. 213.

35. J. G. Traynham, E. E. Green, Y.-S. Lee, F. Schwelngberg, C.-E. Low, I. Amer. Chem. Soc., 24, 6552 (1.972).

36. For a review, see M. L. Poutama, Methods Free-Rad. Chem., 72 (1969).

37. W. A. Thaler, Methods Free-Rad. Chem., 2, 196 (1969).

38. (a) F. F. Rust, W. E. Vaughan, I. Org. Chem., 6, 479 (1941); (b)

A. B. Ash and H. C. Brown, Rec. Chem. Progr., 9, 81 (1948); (c)

H. C. Brown and A. B. Ash, J. Amer. Chem. Soc., 77, 4019 (1955).

38A. G. A. Russel1, J. Amer. Chem. Soc., 72, 2977 (1957).

39. R. Srinivasan and F. I. Sontagg, Can. J. Chem., 47, 1627 (1969).

40. C. Walling and P. S. Fredericks, J. Amer. Chem. Soc., 84, 3326 (1962).

41. M. S. Kharasch, M. Z. Fineman, and F. R. Mayo, J. Amer. Chem. Soc., 61,2139 (1939).

41A. S. W. Benson, J. Chem. Phys., 34,521 (1961).

42. (a) E. C. Kooyman and G. C. Vegter, Tetrahedron, $\underset{\sim}{4}, 382$ (1958); (b) P. D. Bartlett, G. N. Flckes, F. C. Haupt, and R. Helgeson, Accounts Chem. Res., 3, 177 (1970).

43. (a) J. K. Koch1, I. Amer. Chem. Soc., 87, 2500 (1965); (b) J. K. Koch1, J. Org. Chem., 30, 3265 (1965); (c) for a review of decarboxylations by lead tetraacetate, see R. A. Sheldon and J. K. Koch1, Organic Reactions, 12, 279 (1972).

44. D. R. Marshall, P. Reynolds-Warnhoff, E. W. Warnhoff, and J. R. Robinson, Can. J. Chem. , 49, 885 (1971). 
45. P. S. Ske11, D. L. Tuleen, and P. D. Read10, J. Amer. Chem. Soc., 85, 2850 (1963).

46. A Gulllemonat, G. Pelffer, J. C. Traynard, and A. Leger, Bull. Soc. Chim. France, 1192 (1964).

47. L. H. Zalkow and C. D. Kennedy, J. Org. Chem., 22, 1290 (1964).

48. H. W. Johnson, Jr., and D. E. Bublitz, J. Amer. Chem. Soc., 72, 753 (1957).

49. J. C. Martin and P. C. Bartlett, I. Amer. Chem. Soc., 72, 2533 (1957).

50. C. Walling and A. L. Rieger, J. Amer. Chem. Soc., 85, 3134 (1963).

51. (a) For a thorough review of radical brominations, see W. A. Thaler, Methods Free-Rad. Chem., 2,121 (1969); (b) G. A. Russell and H. C. Brown, J. Amer. Chem. Soc., 77, 4578 (1955).

52. J. C. Conly, I. Amer. Chem. Soc., 75, 1148 (1953).

53. J. C. Eck and C. S. Marvel, Org. Syn. Coll., Vol. 2, 74 (1943).

54. P. A. Levene, T. Mor1, and L. A. Mikesa, I. Biol. Chem., 75, 337 (1927).

55. P. I. Abel1 and C. Ch1ao, J. Amer. Chem. Soc., 82, 3610 (1960).

56. J. D. Roberts, E. R. Trumbul1, Jr., W. Bennett, and R. Armstrong, J. Arner. Chem. Soc., 72, 3116 (1950).

57. D. E. Applequist and G. N. Chmurny, J. Amer. Chem. Soc., 82, 875 (1967)

58. (a) H. C. Brown and C. F. Lane, J. Amer. Chem. Soc., 22, 6660 (1970); (b) H. C. Brown and C. F. Lane, Chem. Commun., 521 (1971).

59. J. D. Roberts, W. Bennett, and R. Armstrong, J. Amer. Chem. Soc., I2, $3329(1950)$

60. D. C. Kleinfelter and P. von R. Scheleyer, Org. Syn., 42, 79 (1962). 
61. L.F. Fleser and M. Fleoer, "Reogents for Organic Synthes18", Wiley, New York, N. Y., 1967, p. 865.

62. H. W. Geluk, Synthes18, 2,652 (1970).

63. K. B. Wberg, B. R. Lowry, and T. H. Colby, J. Amer. Chem. Soc., 83. 3998 (1961).

64. E. J. Kupchik and R. J. Kiesel, J. Org. Chem., 22, 764 (1964).

65. J. A. Riddick and W. B. Bunger, "Organtc Solvents", 3rd ed., A. Welssberger, Ed., W1ley, New York, N. Y., 1970 
1. J. K. Koch1, Ed., "Free Rad1cala", Vol. II, W1leym Intersclence, New York, N. Y., 1973.

2. M. L. Poutsma, "Methoda in Free Radical Chemlatry", Vol. I, E. S. Huyser, Ed., Marcel Dekker, New York, 1969, p. 79.

3. W. A. Pryor, "Free Radıcals", McGraw-H111, New York, N. Y., 1966.

4. W. A. Thaler, "Methods in Free Radical Chemistry", Vol. II, E. S. Huyser, Ed., Marcel Dekker, New York, N. Y., 1969, p. 121.

5. C. Walling, "Free Radicals in Solut1on", Wlley, New York, N. Y., 1957.

6. G. H. Williams, "Advances in Free-Radical Chemlstry", Academic Press, New York, N. Y., 1965. 
APPENDIX

NMR SPECTRA 







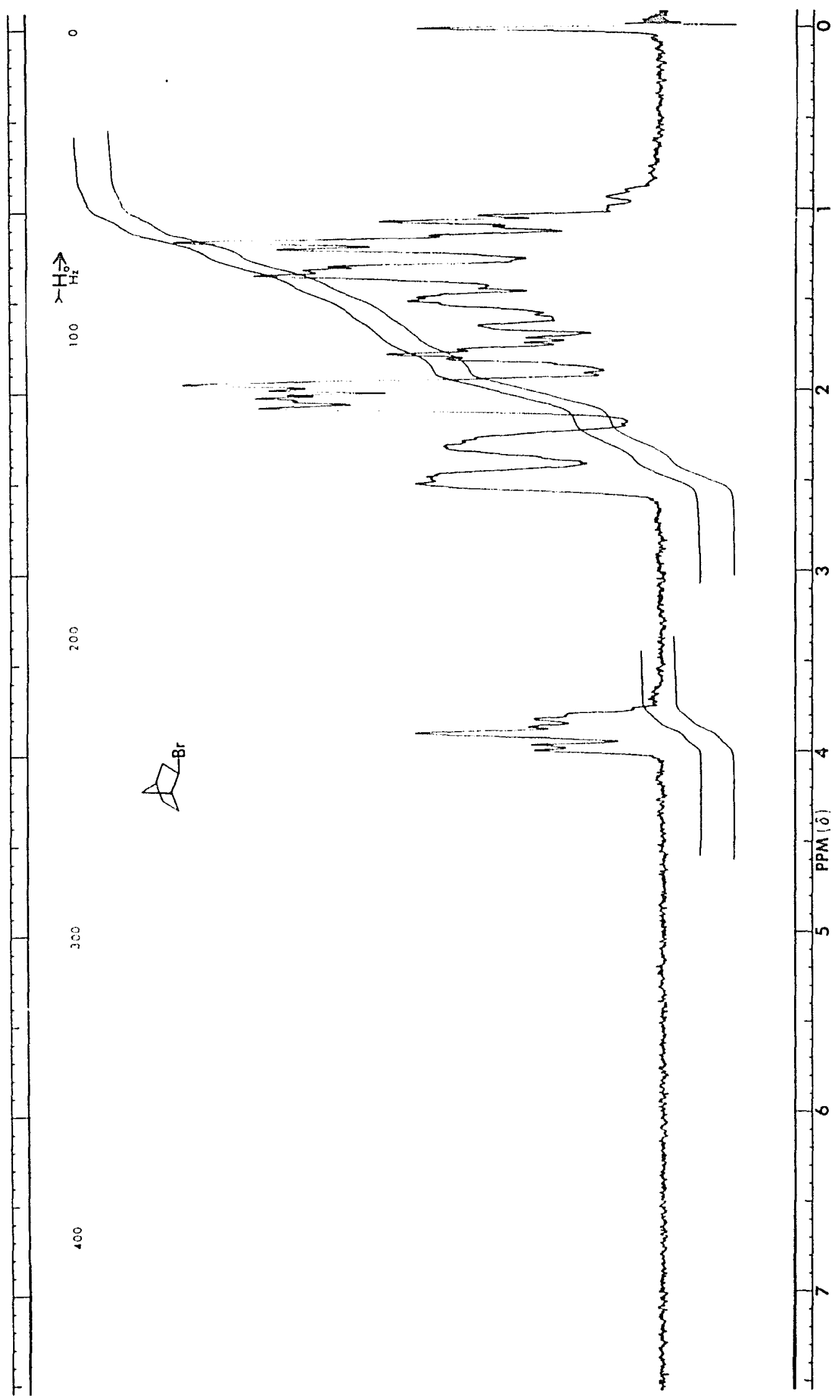




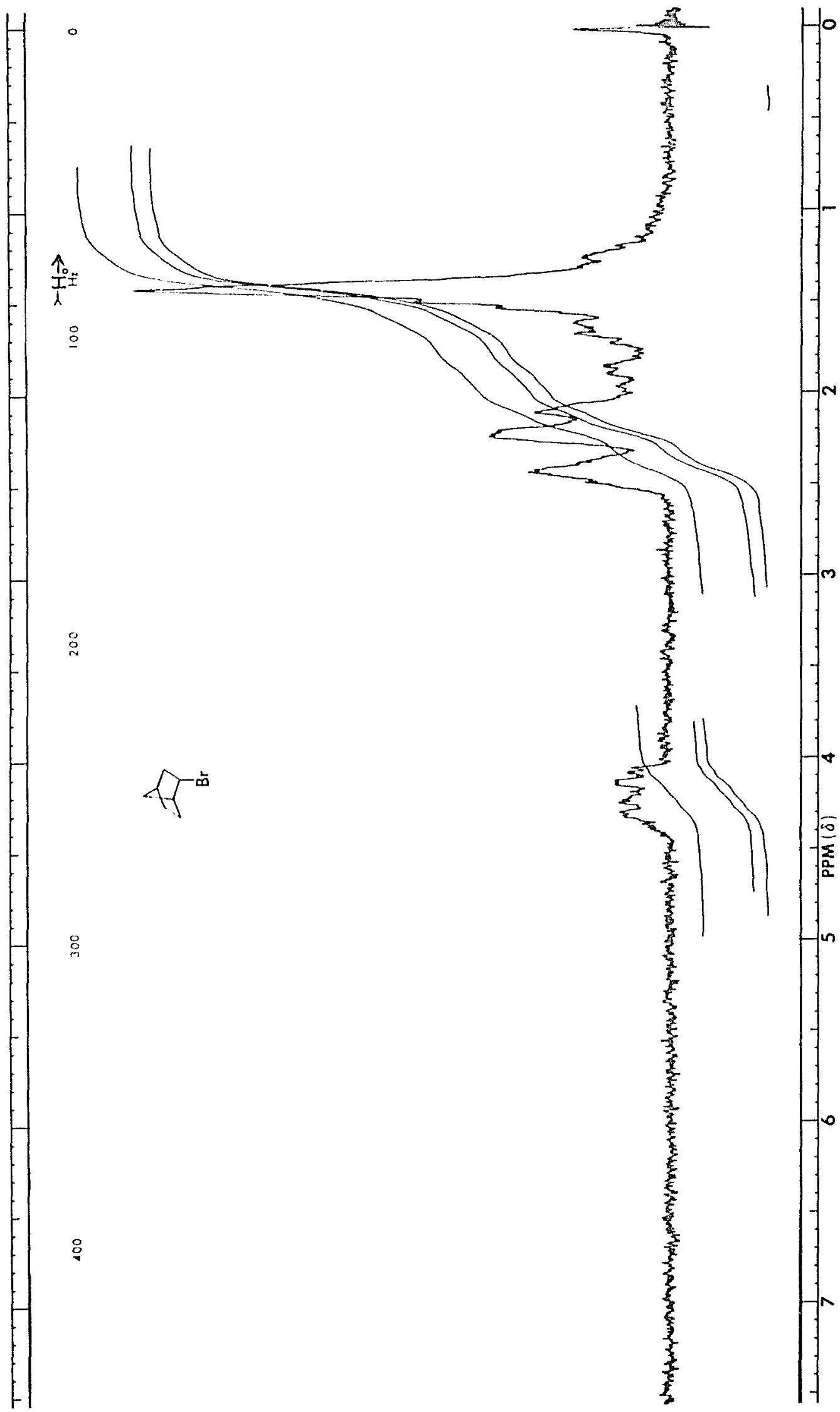




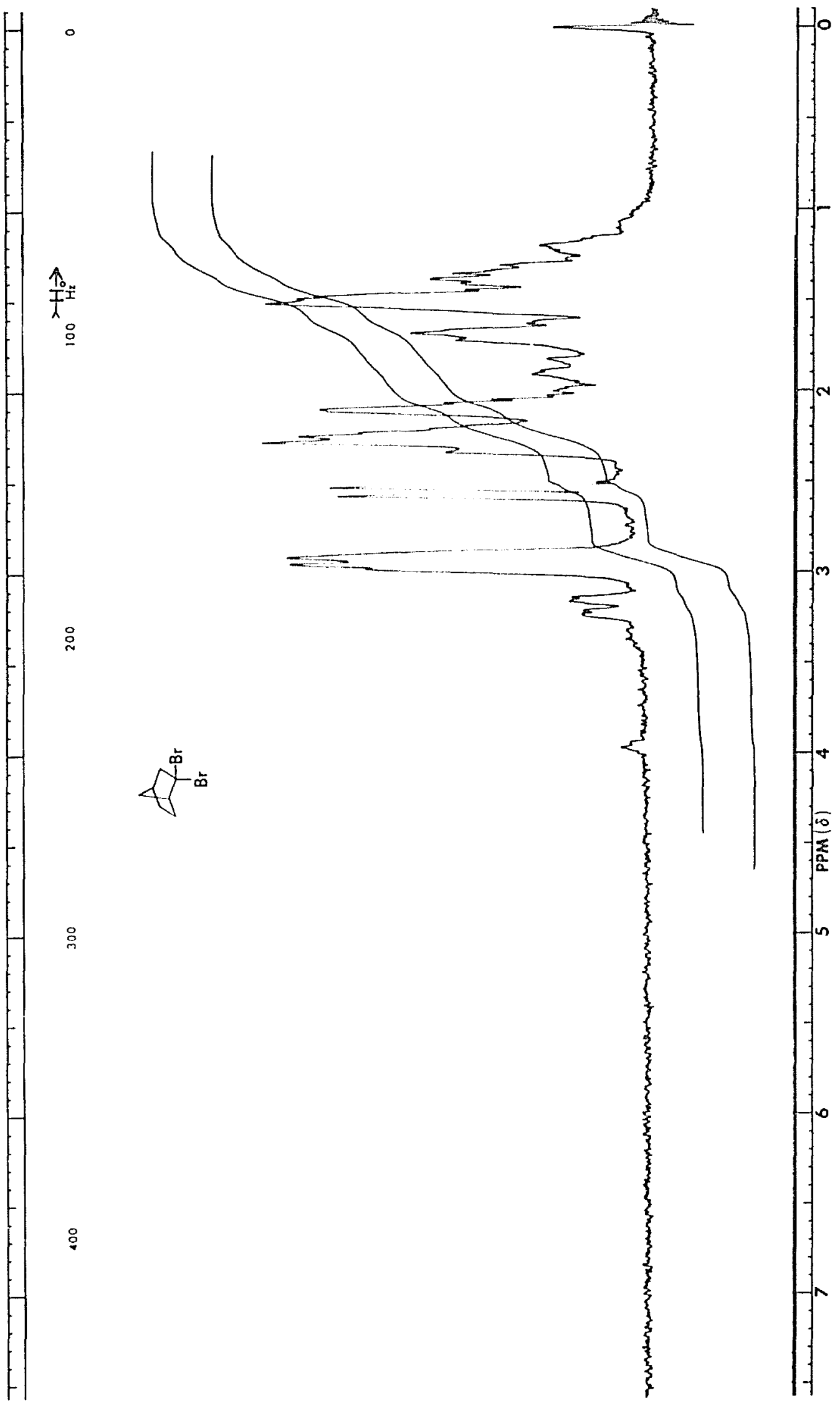


$\frac{\hat{A}}{T^{\prime}}$

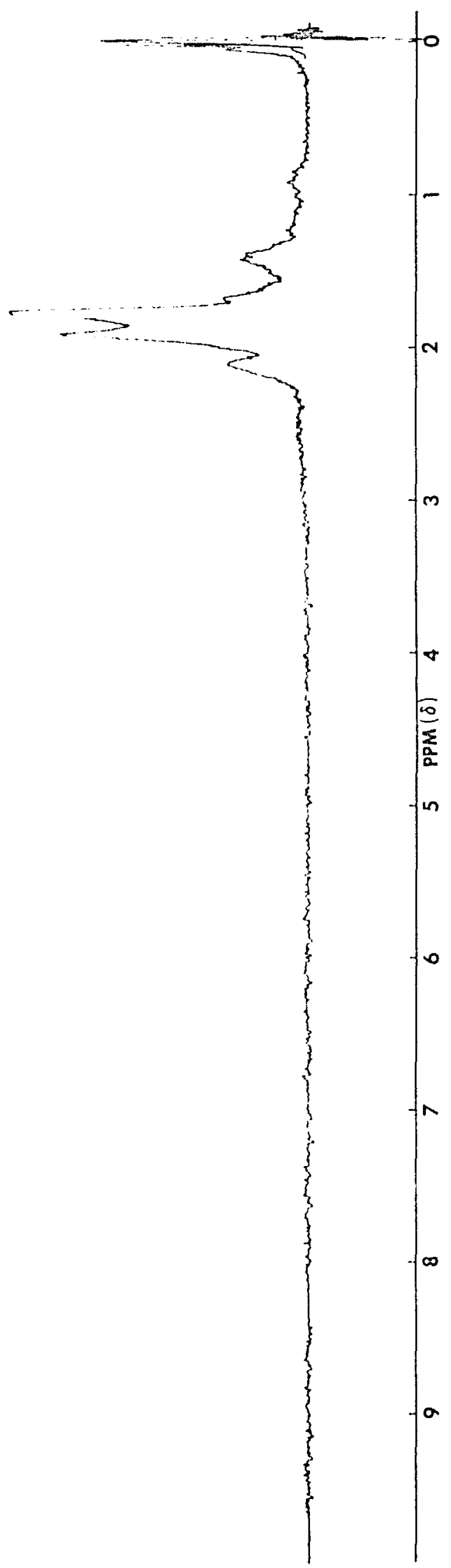

Reproduced with permission of the copyright owner. Further reproduction prohibited without permission. 
Yu-Sun Lee was born on February 6, 1941, in Talpo1, Taiwan, China. He completed his olementary and secondaxy education In Taipei, and entered the Chung Yuan Chrlotian College of Sclance and Englneoring In September 1961. He recelved the degree of Bacholor of scionce in Chemical Englneering in June 1965. Following one year m1litary Bervice In Talwan, he taught in the Chem1Btry Dopartment of Fu Jen University (Talpe1) for two years. He enrolled in the Graduate School of the University of Missour1, Columbia, Missouri, in September 1968, and transferred to the Graduate School of Loulsiana State University in January 1969. He was married to Ya-wen Shth in 1969. He 1s currently a candidate for the Doctor of Philosophy Degree with a major in Organic Chemistry. 
Candidate: Yu-Sun Lee

Major Field: Chemistry

Title of Thesis: Radical Brominations of Alkanic Positions by Bromine and by $\underline{N}$-Bromosuccinimide

Approved:

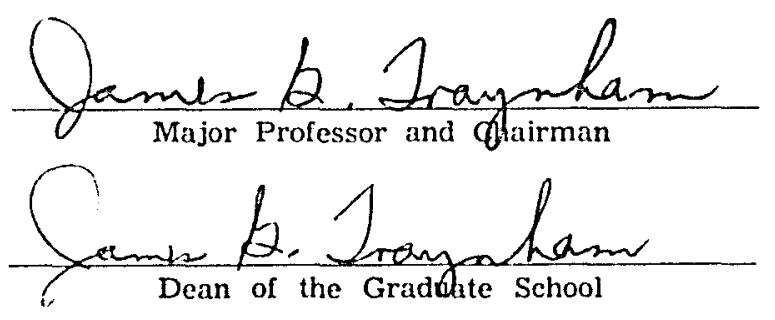

EXAMINING COMMITTEE:

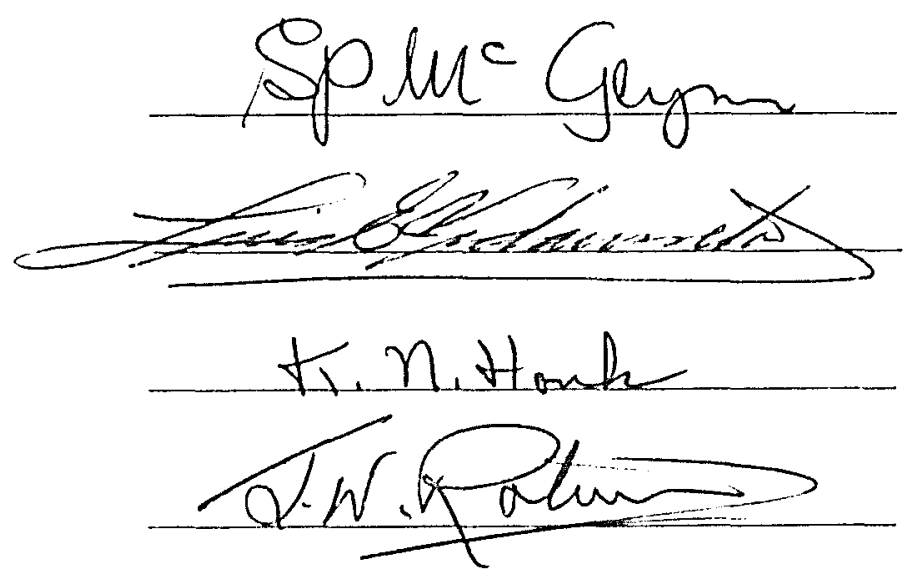

Date of Examination:

Maxch 5, 1974

Reproduced with permission of the copyright owner. Further reproduction prohibited without permission. 